\title{
Proteomic and bioinformatic analysis of outer membrane proteins of the protobacterium Bartonella henselae (Bartonellaceae)
}

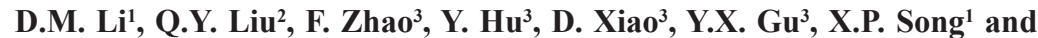
J.Z. Zhang ${ }^{3}$

${ }^{1}$ Department of Vector Biology and Control, National Institute for Communicable Disease Control and Prevention, Chinese Center for Disease Control and Prevention, Beijing, China

${ }^{2}$ State Key Laboratory for Infectious Diseases Prevention and Control, Department of Vector Biology and Control, National Institute for Communicable Disease Control and Prevention, Chinese Center for Disease Control and Prevention, Beijing, China ${ }^{3}$ Diagnosis Department of Infectious Diseases, National Institute for Communicable Disease Control and Prevention, Chinese Center for Disease Control and Prevention, Beijing, China

Corresponding author: J.Z. Zhang

E-mail: Zhangjianzhong@icdc.cn

Genet. Mol. Res. 10 (3): 1789-1818 (2011)

Received November 26, 2010

Accepted February 10, 2011

Published August 26, 2011

DOI http://dx.doi.org/10.4238/vol10-3gmr1153

ABSTRACT. Bartonella henselae, an infectious agent causing catscratch disease and vasculoproliferative disorders in humans, is a fastidious facultative intracellular pathogen. The outer membrane proteins of $B$. henselae are key molecules that play a primary role in host-cell interactions. We isolated $B$. henselae outer membrane proteins, using the ionic detergent N-lauroyl sarcosine sodium salt and sodium carbonate, purification by two-dimensional (2-D) gel electrophoresis, and protein identification using mass spectrometry. Treatment with buffers containing ASB-14 and ZWITTERGENT 3-10 increased solubilization of $B$. henselae proteins, particularly proteins with basic $\mathrm{p} I$. Three hundred and sixty- 
eight spots were detected from the sarcosine-insoluble outer membrane fraction; 94 distinct protein species were identified from 176 spots. In the outer membrane fraction from carbonate incubation, 471 spots were calculated and 259 spots were identified, which included 139 protein entries. There were six outer membrane proteins in the sarcosine-insoluble outer membrane fraction compared with nine outer membrane proteins from samples subjected to carbonate incubation. We used bioinformatic analysis to identify 44 outer membrane proteins by prediction of their domains and tertiary structures and documented the potential virulence factors. We established the 2-D reference maps of the outer membrane subproteome of $B$. henselae using the two different extraction methods, which were partly complementary to each other. Sodium carbonate extraction isolated low-abundance and basic proteins better than the lauroyl sarcosine sodium salt extraction, which enriched high-abundance porins.

Key words: Bartonella henselae; Outer membrane protein; 2-D gel electrophoresis; MS; Bioinformatics

\section{INTRODUCTION}

Bartonella spp is a genus of aerobic, fastidious Gram-negative, facultative intracellular bacilli. Nine of the 21 species identified cause the various Bartonella diseases in human: B. bacilliformis, B. elizabethae, B. henselae, B. quintana, B. koehlerae, B. grahamii, B. vinsonii subsp Berkhoffii, and $B$. vinsonii subsp arupensis. Cat scratch disease (CSD) is a typically benign and self-limiting illness, mostly caused by $B$. henselae. $B$. henselae is detected in association with a wide range of wild and domestic feline hosts and has worldwide distribution. Wild and domestic cats serve as the natural reservoir for $B$. henselae, which establish long-term infections in erythrocytes typically without inducing disease symptoms. If transmitted to humans, who are only an incidental host, $B$. henselae may cause CSD, bacteremia with fever, bacillary angiomatosis and peliosis, endocarditis, and neuroretinitis.

In recent years, studies of Bartonella pathogenesis have taken a major step forward. With regard to the pathogenicity factors of Bartonella, studies point to outer membrane proteins (OMPs) of Bartonella as being important, where they are essential for attachment, invasion, and survival within host cells, as seen in other Gram-negative human pathogenic bacteria (Dehio, 2004). Since OMPs are the interface between the bacterium and the host cells, the outer membrane (OM) and individual OMPs are targeted in developments of diagnostic markers and vaccines against many bacterial diseases. The sarcosine-insoluble OM fraction of $B$. henselae and $B$. quintana was examined in more detail. By means of two-dimensional gel electrophoresis (2-DE) combined with matrix-assisted laser desorption-ionization time-of-flight-mass spectrometry (MALDI-TOF-MS), seven OMPs of $B$. henselae and ten OMPs of B. quintana were previously identified (Rhomberg et al., 2004; Boonjakuakul et al., 2007). Two-dimensional gel electrophoresis is the main platform used in proteomics and has been used in studies on profiling of membrane proteins. Although membrane proteins have been underrepresented in 2-DE gels due to difficulties in extracting and solubilizing them in the isoelectrofocusing (IEF) sample buffer, comparatively high amounts of soluble OMPs, which are potential candidates for diagnosis and vaccination, have been represented in 2-DE gels. 
In recent years, advances in the solubilization of intractable proteins have prompted the proteomic analysis of OMPs, especially in various bacteria including Escherichia coli (Molloy et al., 2000), Aeromonas salmonicida (Ebanks et al., 2005) and Dickeya dadantii (Babujee et al., 2007). Because of the importance of OMPs for the molecular basis of pathogenesis and diagnosis and advances of 2-DE technique, we focused on these fractions and developed a technique for 2-DE of Bartonella OMPs using carbonate incubation compared with sodium lauryl sarcosine incubation for evaluating the differentiation of the two OMP extraction methods, followed by improved solubilization conditions for array by 2-DE using the zwitterionic detergent ZWITTERGENT 3-10, ASB-14 and immobilized $\mathrm{pH}$ gradients. In addition, by exploiting the genome sequence of $B$. henselae strain Houston-1, we scanned in silico for proteins predicted to be localized at the cell surface and compared predicted and experimentally identified $B$. henselae OMPs.

\section{MATERIAL AND METHODS}

\section{Strains and culture conditions}

B. henselae strain Houston-1 (ATCC 49882) was routinely grown on tryptic soy agar containing 5\% defibrinated sheep blood (TSB agar) in a humidified atmosphere with $5 \% \mathrm{CO}_{2}$ at $37^{\circ} \mathrm{C}$ and harvested for protein preparation after 6 days.

\section{Sample preparation of Bartonella OMPs}

\section{Isolation of cell membranes by N-lauroyl sarcosine sodium salt (LSS) method}

The isolation of cell membranes using the LSS (Merck, Germany) method was performed according to Rhomberg's modified procedure (Rhomberg et al., 2004). In brief, $5 \times 10^{8}-1 \times 10^{9}$ colony-forming units $/ \mathrm{mL}$ bacteria were harvested from 6-10 TSB agar plates, washed in low-salt phosphate-buffered saline ( $3 \mathrm{mM} \mathrm{KCl}, 1.5 \mathrm{mM} \mathrm{KH}_{2} \mathrm{PO}_{4}, 68 \mathrm{mM} \mathrm{NaCl}, 9 \mathrm{mM} \mathrm{NaH} \mathrm{PO}_{4}$ ), and pelleted twice by centrifugation at $2500 \mathrm{~g}$ for $10 \mathrm{~min}$ at $4^{\circ} \mathrm{C}$. The pellet was resuspended in $4 \mathrm{~mL}$ hyperosmolar buffer ( $0.2 \mathrm{M}$ Tris, $\mathrm{pH}$ 8.0, $0.5 \mathrm{M}$ sucrose, $250 \mu \mathrm{g} / \mathrm{mL}$ lysozyme, $1 \mathrm{mM}$ EDTA) and incubated at $4^{\circ} \mathrm{C}$ for $1 \mathrm{~h}$. Subsequently, one tablet protease inhibitor cocktail (Roche, Germany) was added, and bacteria were lysed by repeated sonication using a Bandelin HD3200 (single bursts at a $40 \%$ amplitude level for no longer than $5 \mathrm{~s}$ with cooling in ice-cold water to avoid heat denaturation), until the solution turned translucent. Cell debris was removed by centrifugation for 30 $\mathrm{min}$ at $2500 \mathrm{~g}$ at $4^{\circ} \mathrm{C}$. The supernatant was then cleared by centrifugation in a HITACHI CP80MX ultracentrifuge with a P55AT-784 rotor for $90 \mathrm{~min}$ at $100,000 \mathrm{~g}$ at $4^{\circ} \mathrm{C}$. The resulting total membrane pellet was resuspended in a lysis buffer (10 mM HEPES, pH 7.4, 1\% (w/v) lauryl sarcosine), incubated at room temperature for $20 \mathrm{~min}$, and pelleted by ultracentrifugation under the same conditions. The lauryl sarcosine-insoluble pellet that contains the outer membrane-peptidoglycan complex was washed twice in $10 \mathrm{mM}$ HEPES, $\mathrm{pH} 7.4$, to remove residual detergent and centrifuged at $25,000 \mathrm{~g}$ for $30 \mathrm{~min}$ at $4^{\circ} \mathrm{C}$; the washed pellet was then stored at $70^{\circ} \mathrm{C}$.

\section{Isolation of cell membranes by sodium carbonate $\left(\mathrm{Na}_{2} \mathrm{CO}_{3}\right)$ method}

The isolation of cell membranes using the $\mathrm{Na}_{2} \mathrm{CO}_{3}$ method was performed according 
to the procedure modified by Molloy et al. (2000). Briefly, harvesting and washing of bacteria were performed as in the preceding procedure. The pellet was resuspended in $10 \mathrm{~mL} 50 \mathrm{mM}$ Tris- $\mathrm{HCl}$ buffer, $\mathrm{pH} 7.5$, supplemented with the protease inhibitor cocktail. Bacteria were lysed by repeated sonication using a Bandelin HD3200 (single bursts at a 40\% amplitude level for no longer than $5 \mathrm{~s}$ with cooling in ice-cold water to avoid heat denaturation), until the solution turned translucent, and the unbroken cells were removed by centrifugation at $2500 \mathrm{~g}$ for $10 \mathrm{~min}$ at $4^{\circ} \mathrm{C}$. The supernatant was diluted with ice-cold $0.1 \mathrm{M}$ sodium carbonate, $\mathrm{pH} 11$, to a final volume of $50 \mathrm{~mL}$ and stirred slowly for $1 \mathrm{~h}$ at $4^{\circ} \mathrm{C}$. The carbonate-treated membranes were collected by ultracentrifugation in a HITACHI CP80MX P55AT-784 rotor at 100,000 $\mathrm{g}$ for $1 \mathrm{~h}$ at $4^{\circ} \mathrm{C}$. The supernatant was discarded and the membrane pellet was resuspended and washed in 2 $\mathrm{mL} 50 \mathrm{mM}$ Tris- $\mathrm{HCl}$ buffer, $\mathrm{pH}$ 7.5. The pellet was collected by centrifugation at $100,000 \mathrm{~g}$ for 20 min (HITACHI CP80MX P55AT-784 rotor) at $4^{\circ} \mathrm{C}$.

\section{Protein solubilization and quantitation}

Outer membranes were resuspended in the solubilization buffer ( $5 \mathrm{M}$ urea, $2 \mathrm{M}$ thiourea, 2\% CHAPS, $1 \%$ ZWITTERGENT 3-10, 1\% ASB-14, 1\% DTT). To avoid precipitation of urea, the suspension was then centrifuged at $16,000 \mathrm{~g}$ for $15 \mathrm{~min}$ at $23^{\circ} \mathrm{C}$. The supernatant containing solubilized OMPs was collected, protein content quantified by the 2-D QUANT Kit (Amersham Biosciences, USA), and immediately used or stored at $-70^{\circ} \mathrm{C}$.

\section{Two-dimensional electrophoresis}

\section{Isoelectric focusing electrophoresis}

Proteins were separated in the first dimension using the IPGphor ${ }^{\mathrm{TM}}$ isoelectric focusing system (Amersham Biosciences) employing immobilized pH gradient strips (Amersham Biosciences), according to Amersham Biosciences manuals. The OMP samples were focused to their isoelectric points using $24 \mathrm{~cm}$ Immobiline ${ }^{\mathrm{TM}}$ DryStrip gels, $\mathrm{pH}$ 3-10 (Amersham Bioscience) under the following conditions: $30 \mathrm{~V}$ for $5 \mathrm{~h}, 60 \mathrm{~V}$ for $6 \mathrm{~h}, 100 \mathrm{~V}$ for $1 \mathrm{~h}, 300 \mathrm{~V}$ for $1 \mathrm{~h}, 600 \mathrm{~V}$ for $1 \mathrm{~h}, 1000 \mathrm{~V}$ for $1 \mathrm{~h}$, and $8000 \mathrm{~V}$ for $11 \mathrm{~h}$. For the sarcosine-insoluble OMP fraction, $600 \mu \mathrm{g}$ protein was loaded, and for the OMP of sodium carbonate preparations, $800 \mu \mathrm{g}$ was loaded.

Following isoelectric focusing, the proteins were reduced and bound to sodium dodecyl sulfate (SDS) by equilibrating each strip for $15 \mathrm{~min}$ in $10 \mathrm{~mL}$ SDS equilibration buffer ( $50 \mathrm{mM}$ Tris$\mathrm{HCl}, 6 \mathrm{M}$ urea, 30\% (v/v) glycerol, 2\% (w/v) SDS, $0.007 \%$ (w/v) bromophenol blue) containing 100 $\mathrm{mg}$ dithiothreitol (added fresh before use). A second equilibration step in SDS equilibration buffer containing $480 \mathrm{mg}$ iodoacetamide (added fresh before use) instead of dithiothreitol was performed.

\section{SDS-PAGE}

After equilibration, the immobilized $\mathrm{pH}$ gradient strips were loaded onto $12.5 \%(\mathrm{w} / \mathrm{v})$ homogeneous acrylamide gels $(1 \mathrm{~mm}$ thickness $\times 24 \mathrm{~cm}$ width $\times 19 \mathrm{~cm}$ length), sealed with $0.5 \%(\mathrm{w} / \mathrm{v})$ agarose. Protein samples that contained $600 \mu \mathrm{g} \mathrm{LSS}$ and $800 \mu \mathrm{g} \mathrm{Na} \mathrm{CO}_{3}$ of the solubilized membrane proteins were separated by electrophoresis with the Ettan DALT II System (Amersham Biosciences) at $2.5 \mathrm{~W} / \mathrm{gel}$ for $30 \mathrm{~min}$ at $20^{\circ} \mathrm{C}$, and then, the conditions were 
changed to $18 \mathrm{~W} / \mathrm{gel}$ and the gels run until the bromophenol blue dye migrated to about $1 \mathrm{~cm}$ from the bottom of the gel. The gels were kept in the fixing solution (dehydrated alcohol:glacial acetic acid:deionized water; 4:1:5) for 30 min, stained with Coomassie brilliant blue G-250 (Neuhoff et al., 1985) (Bio-Rad, USA) overnight, and destained with 1\% glacial acetic acid.

\section{Analysis of gels}

Individual gels were visualized using an image scanner (Amersham Biosciences) with a transparency adapter using an 8-bit grayscale, 400 dpi. Images were analyzed using the Im-

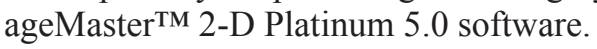

\section{Protein enzymolysis}

All protein spots of stained gels were excised and gel digestion performed as previously described (Zou et al., 2006). The gel pieces were washed with $100 \mu \mathrm{L} 25 \mathrm{mM}$ ammonium bicarbonate, $\mathrm{pH} 8.0$ (Fluka, USA) for $20 \mathrm{~min}$, followed by washing with $50 \mu \mathrm{L} 30 \%$ acetonitrile (Sigma, USA) containing 0.1 M ammonium bicarbonate until the color disappeared, and vacuum freeze-dried. Lyophilized samples were reconstituted in digestion buffer consisting of $25 \mathrm{mM}$ ammonium bicarbonate and $3 \mu \mathrm{L}$ trypsin solution containing $20 \mu \mathrm{g} / \mathrm{mL}$ trypsin (Sigma) and incubated at $37^{\circ} \mathrm{C}$ for $16 \mathrm{~h}$. Supernatants were collected and gel pieces extracted twice with a $40-\mu \mathrm{L}$ extraction buffer containing $50 \%$ acetonitrile and $5 \%$ trifluoroacetic acid (Fluka) for $60 \mathrm{~min}$ each time. The peptide containing supernatant was transferred to a new microtiter plate and pre-frozen at $-80^{\circ} \mathrm{C}$ for $2 \mathrm{~h}$ and then dried under vacuum.

\section{MALDI-TOF-MS}

Lyophilized samples were dissolved in a $2-\mu \mathrm{L}$ solution containing deionized water, $50 \%$ acetonitrile and $0.5 \%$ trifluoroacetic acid, and $0.5 \mu \mathrm{L}$ of the solubilized proteins was mixed with $0.5 \mu \mathrm{L}$ matrix (saturated solution of $\alpha$-cyano-4-hydroxyl-cinnamic acid; Sigma) on a sample plate; the droplet was then left to dry at room temperature. Protein identifications were carried out using a 4700 MALDI-TOF/TOF-MS (Applied Biosystems, Foster City, CA, USA). The mass spectra were obtained using the 4000 Series Explorer ${ }^{\mathrm{TM}}$ software, version 3.0, in the positive ion reflector mode with a mass accuracy of approximately $20 \mathrm{ppm}$. The MALDI-MS was equipped with a 200$\mathrm{Hz}$ frequency-tripled Nd:YAG laser operating at a wavelength of $355 \mathrm{~nm}$. The MS spectra were acquired in the mass range between 800 and $4000 \mathrm{Da}$, using 1500 laser shots.

\section{Database searching}

The experimental MS data were matched to the corresponding virtual peptide mass database derived from the GPS Explorer ${ }^{\mathrm{TM}} \mathrm{v} 3.6$ software (Applied Biosystems) and the Mascot v2.1 software (Matrix Science, London, UK) search protein database and NCBInr database (ftp://ftp.ncbi.nih.Gov/blast/db/FAST/nr.gz) to produce an experimental data set consisting of peptide mass fingerprints. One missed tryptic cleavage, variable modified carboxymethyl, and oxidation were selected. Data were searched at $100 \mathrm{ppm}$ peptide mass tolerance. Identifications with a GPS confidence interval greater than $95 \%$ were accepted. 


\section{In silico analysis}

Theoretical mass, $\mathrm{p} I$ and grand average of hydropathy (GRAVY) values of OMP candidates were calculated using the ProtParam tool (http://www.expasy.ch/tools/protparam.html) (Gasteiger et al., 2005). SignalP 3.0 server (http://www.cbs.dtu.dk/services/SignalP/) was used to hypothesize N-terminal secretory signal peptides of the identified proteins. HMMTOP version 2.0 (Tusnády and Simon, 2001) (http://www.enzim.hu/hmmtop/index.html) was used to predict transmembrane helices in the identified proteins. Predicted Subcellular Localization of OMPs of $B$. henselae strain Houston-1 was downloaded from the databases of PSORTdb (http://db.psort.org/) (Rey et al., 2005) and Proteome Analyst PA-GOSUB 2.5 (http://www.cs.ualberta.ca/ bioinfo/PA/ GOSUB/) (Lu et al., 2004). Potential domains were identified by use of InterPro (http://www.ebi. ac.Uk/interpro/) and Pfam 24.0 (http://pfam.sanger.ac.uk/). Secondary and tertiary structure predictions were performed using SOPMA (Geourjon and Deleage, 1995), MODBASE (http://modbase. compbio.ucsf.edu/ModWeb20-html/modweb.html) (Pieper et al., 2009) and SWISS-MODEL (http://swissmodel.expasy.org//SWISS-MODEL.html) (Arnold et al., 2006).

\section{RESULTS}

\section{2-DE of LSS method and the in silico analysis of protein assignment}

Spot pattern and resolution of the two independent gels from two replicate samples were highly reproducible (Appendix Figure 1). In total, about 368 protein spots were exhibited on the 2-DE gels, and 176 spots belonging to $B$. henselae were verified by MS and searching NCBI nr databases for the $B$. henselae ATCC 49882 genome sequence (Alsmark et al., 2004) (Figure 1).

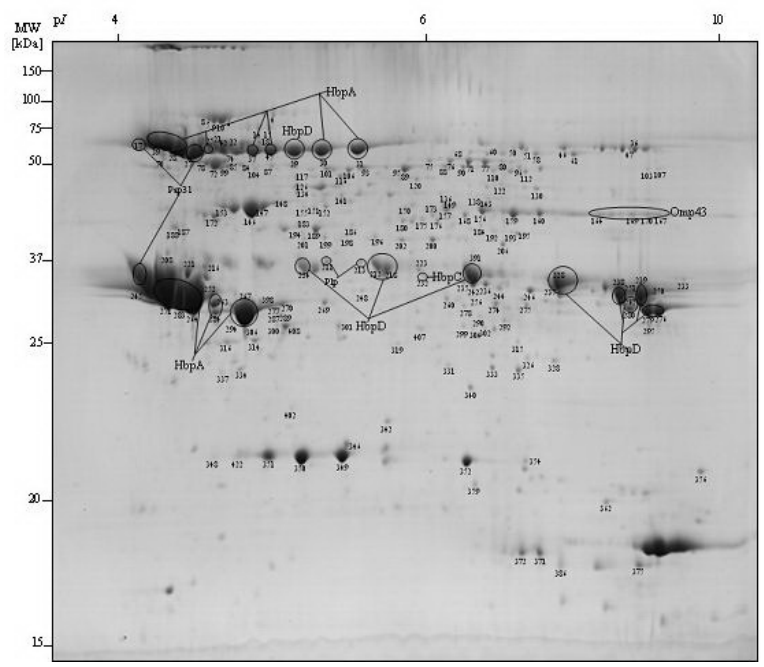

Figure 1. Sarcosine insoluble Bartonella henselae Houston-1 outer membrane proteins (OMPs) separated by 2-DE using pH 3-10 IPG and 12.5\% SDS-PAGE. Proteins were stained with Coomassie brilliant blue G-250; spots were excised individually and then identified by peptide mass fingerprints (PMF). Each number indicates a protein for which a PMF identity was obtained; these numbers correspond to the protein identities shown in Appendix Table 1 and Appendix Table 2. Proteins in circles are annotated as OMPs. 
The 176 spots (predicted $\mathrm{p} / \mathrm{s}$ ranging from 4.81 to 9.33 and molecular mass ranging from 15.64 to $80.6 \mathrm{kDa}$ ) representing 94 different proteins belonged to 6 OMPs, 6 periplasmic (PP) and inner membrane proteins (IMPs), 59 cytoplasmic proteins (CPs) and 23 proteins with unknown subcellular localization. Of the identified proteins, 16 proteins possessed a GRAVY-value $>0$, indicating that some hydrophobic proteins were also isolated by this approach, including malate dehydrogenase, a hydrophobic protein with the highest GRAVY value (0.311) (Appendix Table 1).

To further characterize the proteins with unknown subcellular localization, in silico predictions by means of SignalP, HMMTOP, Pfam, and PA-SUB were carried out. There were only 7 proteins whose location could be predicted, including 5 CPs, 1 IMP and 1 PP (Appendix Table 2).

\section{2-DE of $\mathrm{Na}_{2} \mathrm{CO}_{3}$ method and the in silico analysis of protein assignment}

Spot pattern and resolution of the two independent gels from two replicate samples were highly reproducible (Appendix Figure 2). In total, about 471 protein spots were detected and 259 spots belonging to $B$. henselae were verified by MS and searching NCBI nr databases for the $B$. henselae ATCC 49882 genome sequence (Alsmark et al., 2004) (Figure 2). The 259 spots (predicted $\mathrm{p} / \mathrm{s}$ ranging from 4.78 to 9.75 and molecular mass ranging from 15.7 to $89.0 \mathrm{kDa}$ ) representing 139 different proteins belonged to 9 OMPs, 8 PP and IMPs, 87 CPs and 35 proteins with unknown subcellular localization. Of the identified proteins, 28 proteins possessed a GRAVY-value $>0$, indicating that some hydrophobic proteins were also isolated by this approach, including malate dehydrogenase, a hydrophobic protein with the highest GRAVY value (0.311) (Appendix Table 3).

By using SignalP, HMMTOP, Pfam, and PA-SUB for analysis of the proteins with unknown subcellular localization, there were 8 proteins with signal peptides and 15 proteins

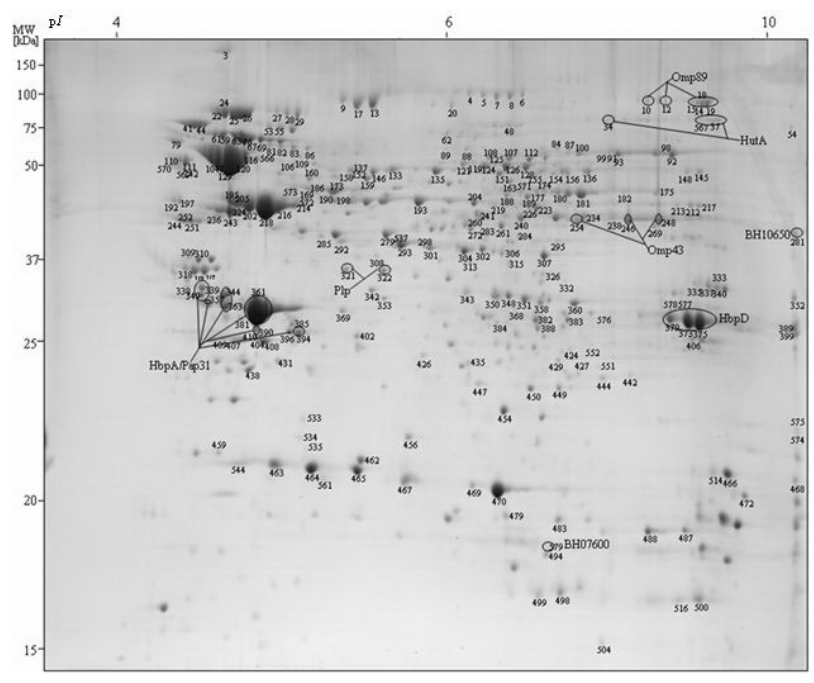

Figure 2. Carbonate insoluble Bartonella henselae Houston-1 outer membrane proteins (OMPs) separated by 2-DE using pH 3-10 IPG and 12.5\% SDS-PAGE. Proteins were stained with Coomassie brilliant blue G-250; spots were excised individually and then identified by peptide mass fingerprints (PMF). Each number indicates a protein for which a PMF identity was obtained; these numbers correspond to the protein identities shown in Appendix Table 3 and Appendix Table 4. Proteins in circles are annotated as OMPs. 
with 1 to 3 transmembrane helices in these proteins, of which 7 were assigned to CPs, IMP and PP (Appendix Table 4).

\section{Comparison of MS identification results between $\mathrm{LSS}$ and $\mathrm{Na}_{2} \mathrm{CO}_{3}$ methods}

In summary, six OMPs, including HbpA, HbpD, HbpC, Omp43, Pap31, and Plp, were identified using the LSS method. Besides, HbpA, HbpD, Omp43, Pap31, Plp, HutA, Omp89, $\mathrm{BH} 10650$, and $\mathrm{BH} 07600$ were extracted by using the $\mathrm{Na}_{2} \mathrm{CO}_{3}$ method. The differences between the two OMP purification methods are listed in Table 1.

\begin{tabular}{lcccc}
\multicolumn{4}{l}{ Table 1. Comparison of mass spectrometry identification results between LSS and $\mathrm{Na}_{2} \mathrm{CO}_{3}$ methods. } \\
\hline Subcellular location & LSS method specific & $\mathrm{Na}_{2} \mathrm{CO}_{3}$ method specific & Common & Total \\
\hline Outer membrane & 1 & 4 & 5 & 10 \\
Periplasm and inner membrane & 2 & 5 & 4 & 11 \\
Cytoplasm & 9 & 37 & 49 & 95 \\
Unknown & 9 & 20 & 74 & 43 \\
Total & 21 & 66 & 72 & 159 \\
\hline
\end{tabular}

LSS $=$ N-lauroyl sarcosine sodium salt method; $\mathrm{Na}_{2} \mathrm{CO}_{3}=$ sodium carbonate method.

\section{Characteristics of $B$. henselae OMPs identified}

We identified a total of 10 OMPs, including HbpA, HbpD, HbpC, Pap31, Omp43, Plp, HutA, Omp89, BH10650, and BH07600, using the LSS and $\mathrm{Na}_{2} \mathrm{CO}_{3}$ methods (Table 2). Many of the OMPs were resolved into more than two protein species, although in some cases only a single-charged species was observed (e.g., HbpC), while for others (e.g., HbpA), multiplecharged protein species existed. Furthermore, 2-DE of LSS showed that two clusters of mass for $\mathrm{HbpA}$ and $\mathrm{HbpD}(25-30$ and $68 \mathrm{kDa})$ existed.

To investigate potential functions of these OMPs of $B$. henselae, the Pfam database was searched for accessory domains. The proteins HbpA, HbpD, HbpC, Pap31, and Omp43 have features of porins. Plp is peptidyl-prolyl cis-trans isomerase, containing isomerase and rotamase domains. HutA, heme receptor, was found to have a tonB-dependent receptor plug domain.

Omp89, 798 AA, was an OMP of unknown function of B. henselae. The Pfam database indicated that there were five surface antigen variable number repeat domains (39106AA, 107-184AA, 187-275AA, 278-357AA, 360-433AA) in the N-terminus of the amino acid sequence and one surface antigen domain (463-798AA) in the C-terminus. It exhibited 74-91 and 56-58\% identity to the corresponding protein of Bartonella spp and Brucella spp, respectively. The second structure prediction using SOPMA exhibited $24.94 \%$ alpha helix, $26.69 \%$ extended strand, $6.52 \%$ beta turn, and $41.85 \%$ random coil.

BH07600, 159AA, was a putative uncharacterized protein with no functional annotation in Uniprot, and one SmpA_OmlA hit in the Pfam database. It is an OM lipoprotein exhibiting $78-84 \%$ amino acid identity to the homologous protein of Bartonella spp (based on the whole genome sequence of $B$. bacilliformis, B. tribocorum, B. quintana, and B. grahamii, available in the database) and $55-56 \%$ to that of Brucella spp. The second structure prediction exhibited $13.84 \%$ alpha helix, $30.82 \%$ extended strand, $11.95 \%$ beta turn, and $43.40 \%$ random coil by consensus prediction from multiple alignments. 
Proteomic and bioinformatic analysis of Bartonella henselae

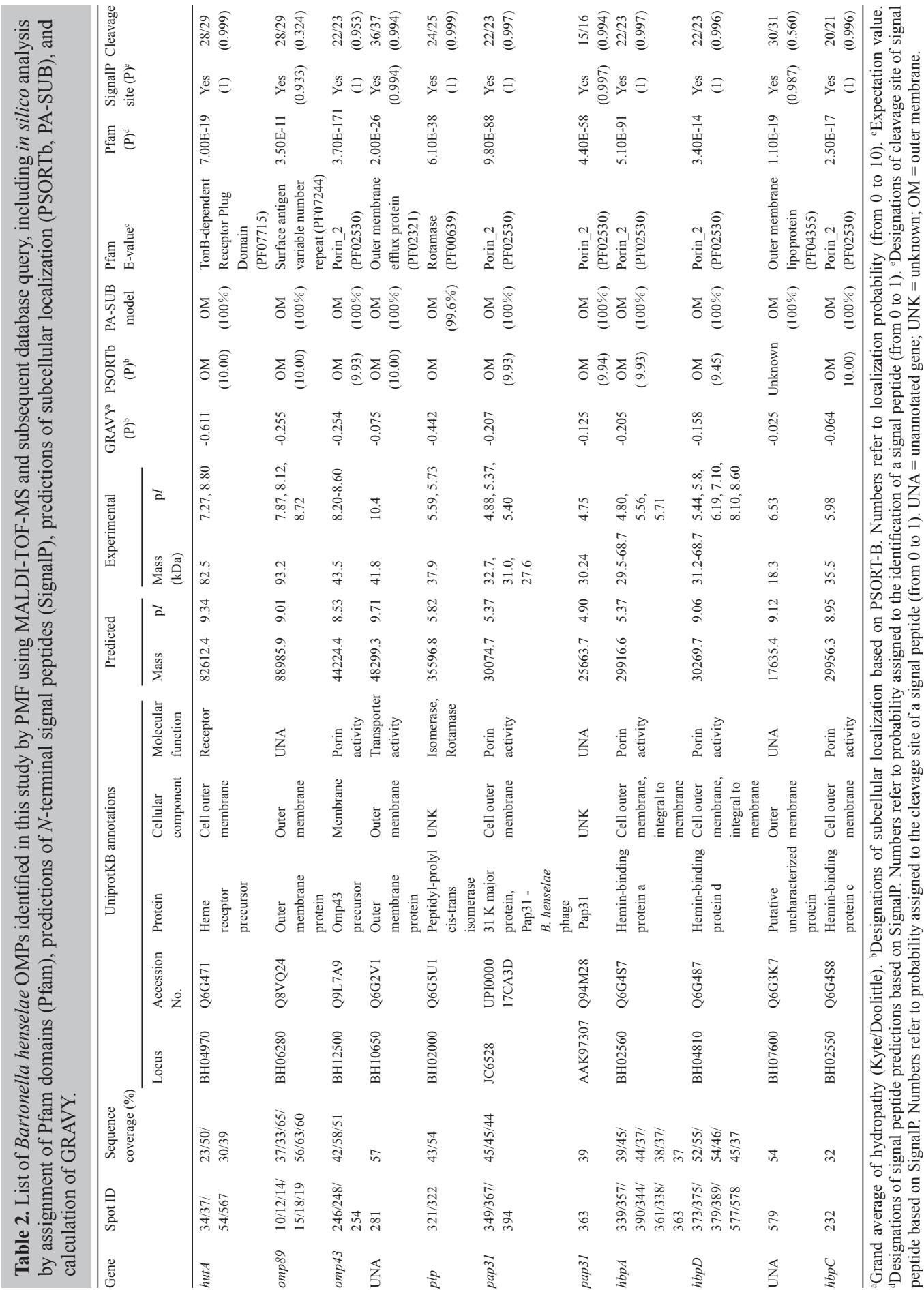


BH10650, 440AA, was a bona fide OMP of $B$. henselae, which was identified as a presumptive outer membrane efflux protein (the OEP family) with Pfam (2 OEP domain hits), related to the type I secretion OMP, TolC of Escherichia coli. It exhibited $62-89 \%$ and $50 \%$ identity to the corresponding protein of Bartonella spp and Brucella spp. The second structure prediction exhibited $69.77 \%$ alpha helix, $5.23 \%$ extended strand, $2.05 \%$ beta turn, and $22.95 \%$ random coil.

\section{Analysis of the in silico OM subproteome of $B$. henselae}

PSORTdb (Rey et al., 2005), Proteome Analyst PA-GOSUB 2.5 (Szafron et al., 2004) and UniProt were interrogated to retrieve all $B$. henselae proteins annotated as OMPs (including hypothetical proteins) (Table 3). Twenty-nine OMPs were predicted by PSORTdb, except for DNA topoisomerase I, which was a chromosome component, and Plp and BH07600 were not predicted but detected in our study. There were 38 predicted OMPs using PA-GOSUB, and a total of 44 proteins were located on the outer membrane after removing the repetitive proteins in the two predicted results and UniProt. Of the 44 OMPs with $\mathrm{p} I 4.94-10$, the predicted molecular mass ranged from $11.70 \mathrm{kDa}$ for $\mathrm{VirB} 3$ to $323.67 \mathrm{kDa}$ for BadA1, and there were 7 of these proteins with predicted molecular mass $>100 \mathrm{kDa}$ and 19 OMPs with predicted $\mathrm{p} I>9$. Forty-one OMPs were predicted to be hydrophilic using the ProtParam tool, and 29 gene products were predicted by SignalP to possess an N-terminal secretion signal. To further substantiate this analysis, in silico predictions by means of Pfam, MODBASE, and SWISS-MODEL were carried out. Table 3 lists the 44 predicted OMPs, whose putative function was predicted based on domain and homology search results, including adhesion-associated proteins (e.g., BadA1 (Riess et al., 2007), filamentous hemagglutinin, etc.), autotransporters in the type V secretion systems (e.g., BH13140, BH13180, etc.), type IV secretion system protein VirB3, tonB-dependent receptor (HutA), porins (e.g., $\mathrm{HbpA}, \mathrm{HbpB}, \mathrm{HbpC}$, and $\mathrm{HbpD}$ ), hemolysin activation protein Hec, peptidoglycan-associated lipoprotein Pal transferase (BH11350), and others.

\section{DISCUSSION}

The bacterial OMPs mediating adhesion and host immune evasion between Bartonella and its hosts are critical targets of the host's immune response, often having diagnostic relevance, and are potential candidate antigens for vaccine developments. To date, there are only two studies that identified Bartonella surface proteins, including OMPs, using proteomic methods, namely 2-DE and MALDI-TOF-MS (Rhomberg et al., 2004; Boonjakuakul et al., 2007). These two reports mostly focused on the OM compartment prepared with lauryl sarcosine in order to identify potential pathogenicity factors of $B$. henselae (Rhomberg et al., 2004) and to identify the predominant B. quintana antigens (Boonjakuakul et al., 2007). Seven proteins (of 53 proteins analyzed) and 10 proteins (of 60 proteins analyzed), respectively, were identified as prototypical OMPs; however, PSORTb predicts a significantly higher number of OMPs in $B$. henselae. Thus, our aims were to develop a better method for the isolation of Bartonella OMPs and to further describe the OM subproteome of $B$. henselae based on 2-DE gels. Molloy et al. (2000) identified 21 of $26(80 \%)$ of the predicted integral OMPs of $E$. coli that are annotated in SWISS-PROT release 37 using sodium carbonate extraction, which was the more efficient method for the isolation of Bartonella OMPs.

We analyzed the OM proteome of $B$. henselae by using the sarcosine- and carbonateinsoluble OM fraction (Figure 3). We identified six sarcosine-insoluble OMPs including HbpA, 
Proteomic and bioinformatic analysis of Bartonella henselae

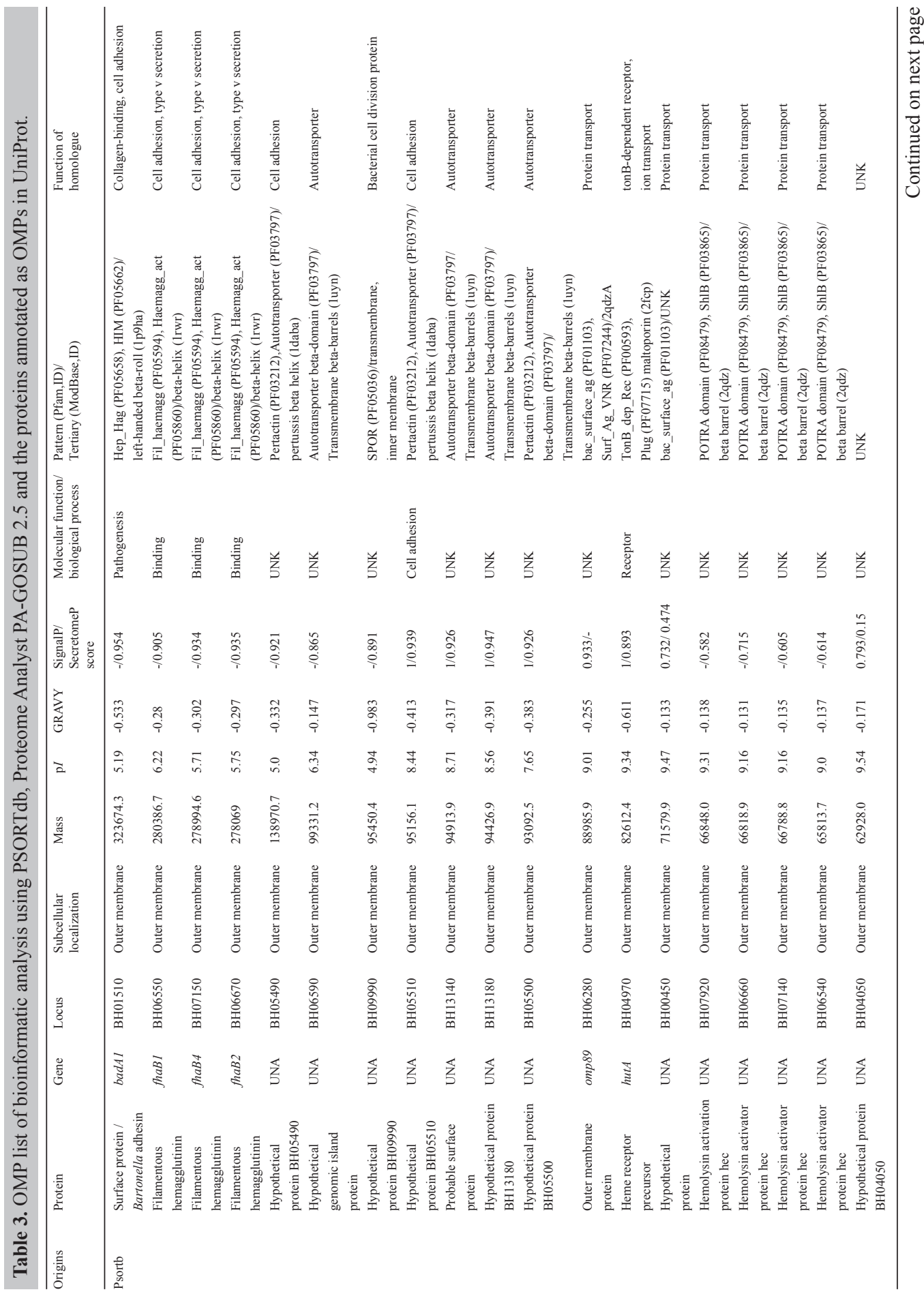

Genetics and Molecular Research 10 (3): 1789-1818 (2011) 
D.M. Li et al.

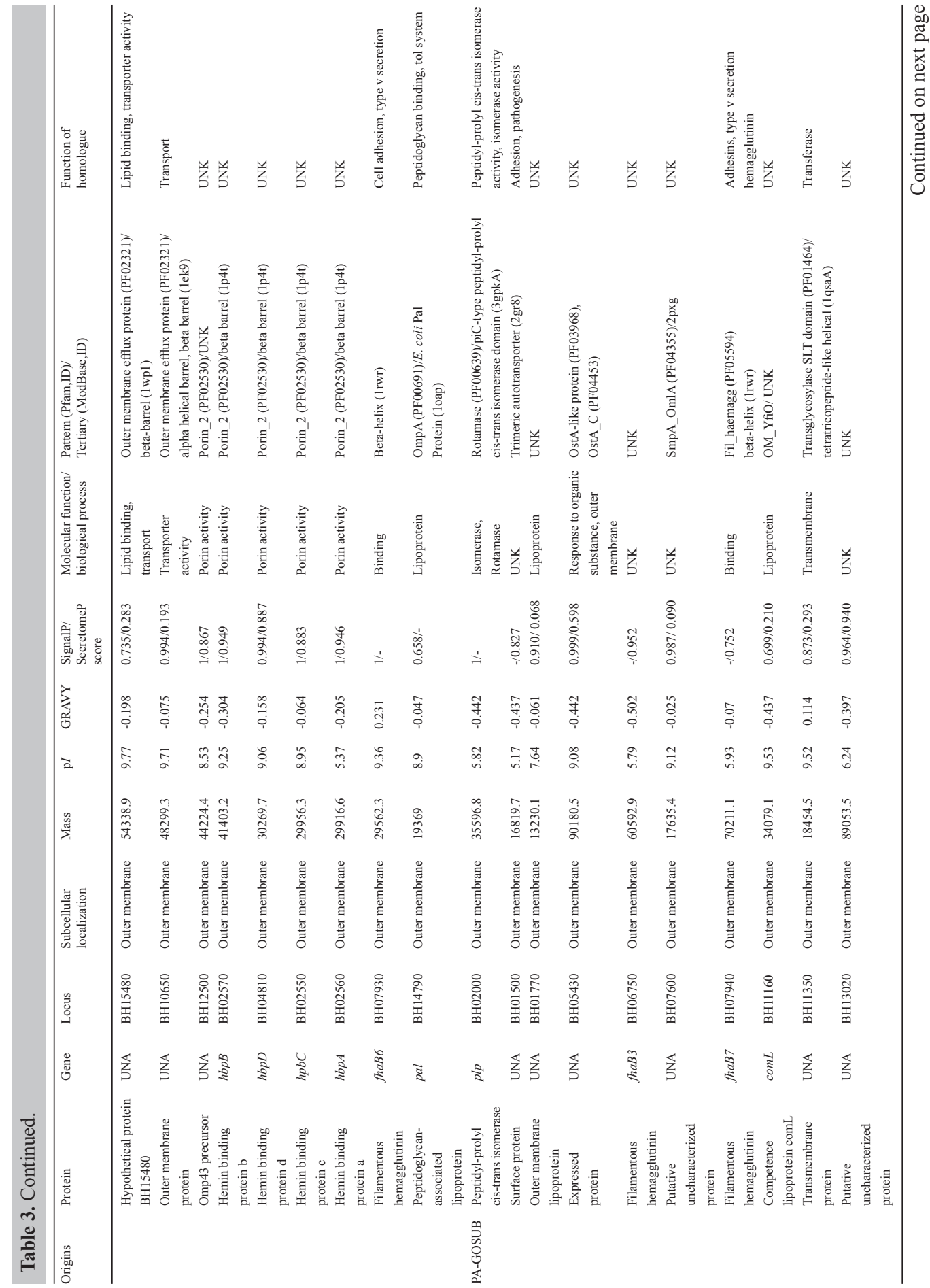


Proteomic and bioinformatic analysis of Bartonella henselae

1801

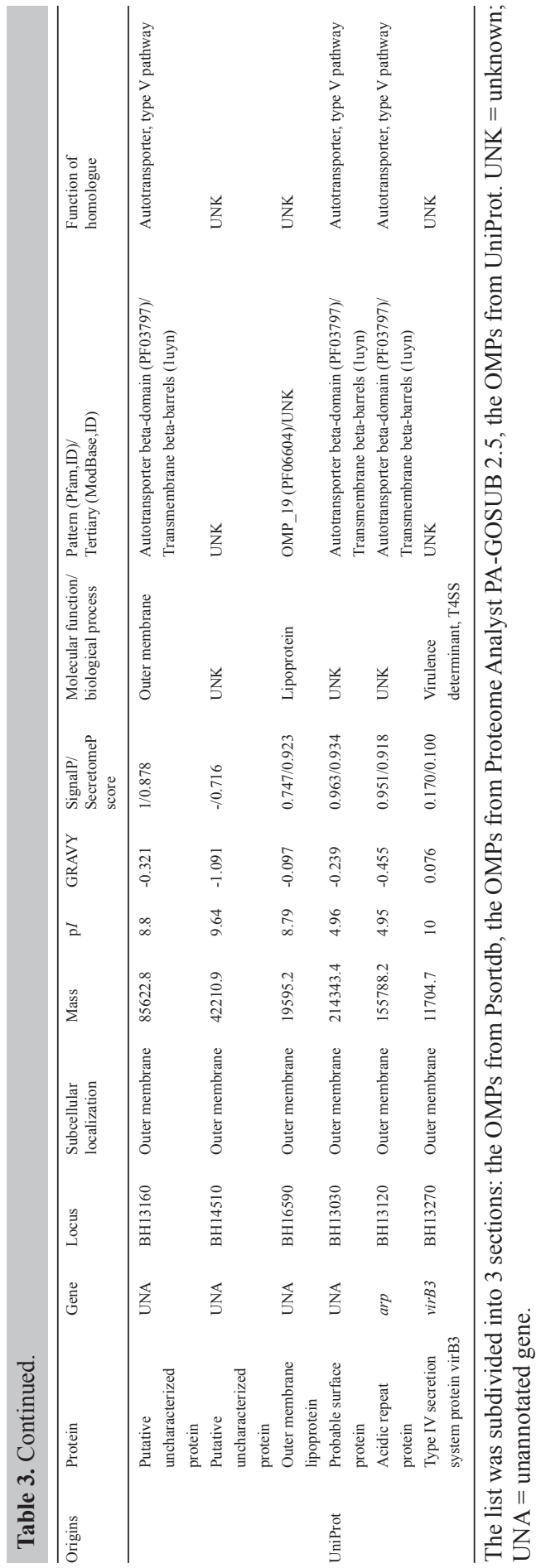


$\mathrm{HbpD}, \mathrm{HbpC}$, Omp43, Pap31, and Plp. Sodium carbonate treatment resulted in the isolation of four additional proteins, including Omp89, HutA, BH10650, and BH07600 (Figure 3). Different 2-DE maps were obtained for OM proteins extracted using the LSS and carbonate methods. LSS OM protein fraction was enriched with the Hbp proteins, which are the products of the $h b p C A B / D$ locus. HbpA and HbpD had the highest abundance among all identified OMPs and were detected as a cluster of proteins with different molecular mass of 25-30 kDa, corresponding to studies by Rhomberg et al. (2004) and Chenoweth et al. (2004); however, the higher molecular mass forms of $68 \mathrm{kDa}$ were also expressed. The carbonate method provided better conditions to detect the alkaline protein fraction, including Omp89, HutA, BH10650, and BH07600, which were alkaline proteins except for the common OMPs with the LSS methods.

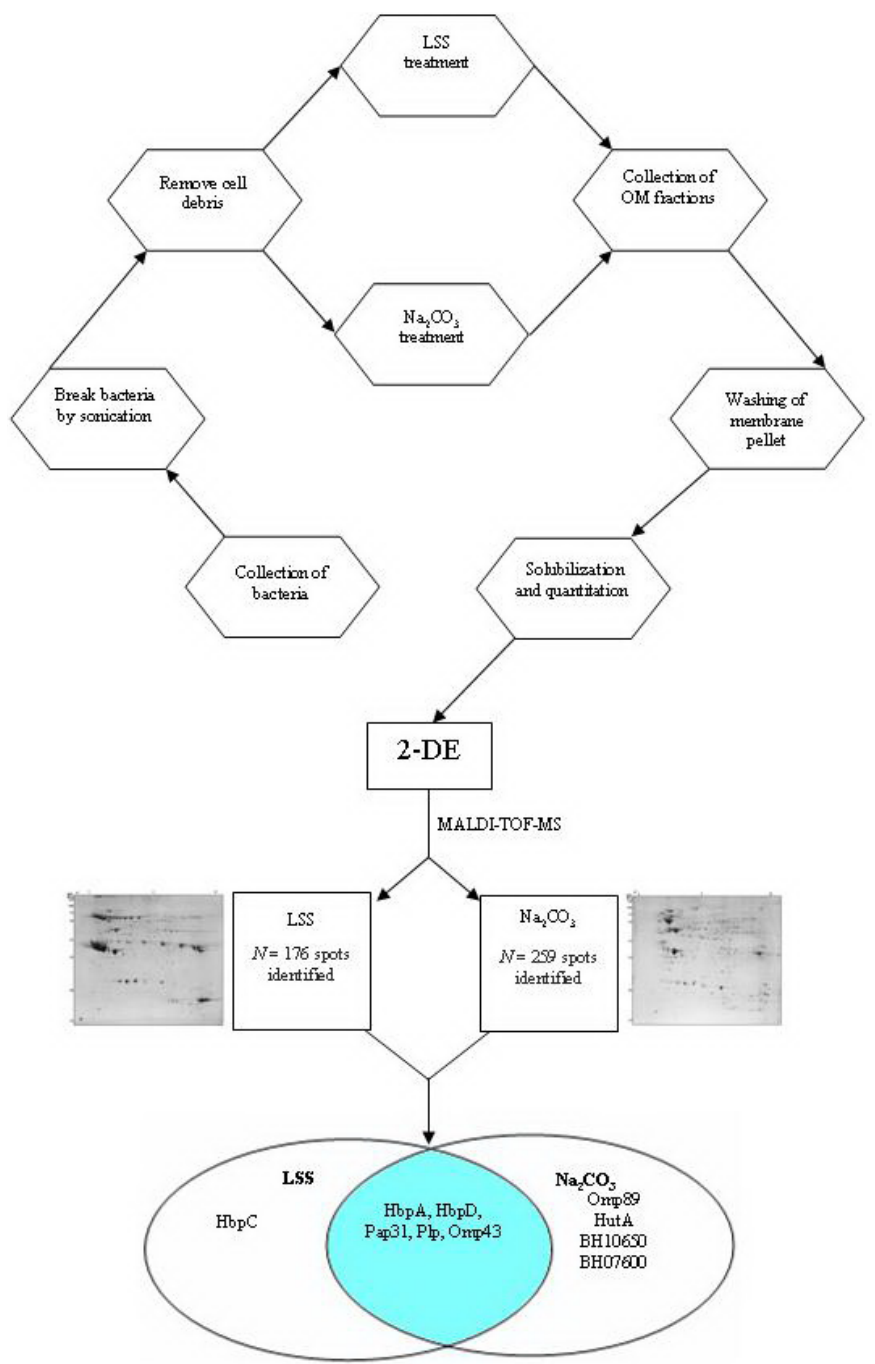

Figure 3. Workflow for sample preparation and numbers $(N)$ of identified proteins and outer membrane proteins (OMPs) of Bartonella henselae. 
The hemin-binding proteins, $\mathrm{HbpA}, \mathrm{HbpD}$ and HutA, cell adhesion-associated protein Omp43 (Burgess et al., 2000), Omp89 and Plp have previously been identified in the sarcosine-insoluble OM fraction of $B$. henselae (Rhomberg et al., 2004). Hbp family members, which are homologous to B. henselae Pap31 (Zimmermann et al., 2003), Brucella Omp31, Agrobacterium tumefaciens Omp25 and Neisseria meningitides opacity proteins, contain eight $\beta$-barrel transmembrane domains and four extracellular loops (Minnick et al., 2003). HbpA plays an active role in hemin acquisition (Carroll et al., 2000), and the other Hbp family members constitute a compensatory iron-acquisition system important for $B$. henselae survival (Burgess et al., 2000). Omp43, which is a porin, and OM antigen and Omp89, which appeared to produce the strongest humoral response (Chenoweth et al., 2004), as the three major putative Fn-binding proteins, may play an important role in $B$. henselae adherence to and invasion of host cells (Dabo et al., 2006). We identified two hypothetical proteins, BH07600 and BH10650. BH07600, an OM lipoprotein, is possibly involved in maintaining the structural integrity of the cell envelope (Ochsner et al., 1999). BH10650 is a putative outer membrane efflux protein, which forms trimeric channels involved in the export of a variety of substrates in Gram-negative bacteria, such as E. coli (Higgins et al., 2004). Outer membrane protein TolC is the prototypical OM channel component involved in multi-drug resistant and type I secretion, which belongs to the resistance-nodulation-cell division protein family involved in the transport of various drugs across the cell envelope in bacteria; it exhibits broad substrate specificity and acts like an efflux pump (Yang et al., 2003; Hernandez-Mendoza et al., 2007). Antibiotic substrates of the drug efflux pump include erythromycin, tetracycline, chloramphenicol, ampicillin, and rifampin (Okusu et al., 1996; Zgurskaya and Nikaido, 1999), which are the preferred antibiotic treatments for Bartonella infections. Bartonella are susceptible to many antibiotics in vitro (including $\beta$-lactams, aminoglycosides, chloramphenicol, tetracyclines, macrolides, and rifampicin) (Maurin et al., 1995). Conversely, clinical data indicate that the bacteria may be more resistant in vivo. For Bartonella, in which potential mechanisms of drug efflux are not known, the other antibiotic resistance systems such as tetracycline resistance protein and macrolide-specific efflux proteins were identified by in silico genome analysis of Bartonella (Biswas et al., 2008), suggesting that some drug resistance systems including BH10650 may play an important role in vivo or in overexpressions.

One of the major problems encountered in membrane protein studies are the difficulty to solubilize these hydrophobic proteins using solutions compatible with their subsequent separation, digestion, and/or identification by MS analysis (Tan et al., 2008). The application of zwitterionic detergents such as ZWITTERGENT 3-10 and ASB-14 significantly increased the solubilization of the OMPs in the IEF sample buffer and resulted in the identification of more protein spots, especially in the alkaline $\mathrm{p} I$ range. Although a higher yield of extracted proteins was detected on the 2-DE gels, their MS identification may be incomplete due to i) the inherent lack of trypsin cleavage sites in these proteins, ii) poor accessibility to proteases in these regions, iii) tendency of the hydrophobic domains to aggregate and precipitate after the removal of SDS, and iv) difficulties in extracting these proteins (Tan et al., 2008). It has been well documented that cytoplasmic and periplasmic components and inner membrane proteins are present as contaminants in the OM preparation. This partially reflects their surface localization (e.g., ATPase, chaperon GroEL, FAD, NADH/NADPH-proteins), as well as the tight association between the inner and outer membranes or a technical artifact. The other components from the Bartonella cells besides OMPs were shown on the 2-DE profiles as we 
increased the sample amounts compared with the previous studies (Molloy et al., 2000; Rhomberg et al., 2004) to detect more low-abundance OMPs.

Despite all this, the inherent limitation of solubility of membrane proteins in 2-DE (Jungblut et al., 2010) rendered our results with distinct differences relative to the OMPs from the in silico genome analysis. There were 44 OMPs predicted by the two predictor programs along with the Uniprot. There could have been multi-transmembrane alpha helix or $\beta$-barrel proteins in the 162 hydrophobic proteins from the predicted 540 proteins with unknown localization (data not shown). Therefore, it is possible that more $B$. henselae OMPs will be identified when optimized methods for their isolation become available.

Among the 44 predicted OMPs, 7 OMPs with molecular mass $\geq 100 \mathrm{kDa}$, including adhesin BadA, filamentous hemagglutinin and autotransporters, and 6 OMPs with $\mathrm{p} I \geq 9.5$, including VirB3, ComL and hypothetical proteins, which exceeded the resolution capacity of the $\mathrm{pH}$ 3-10 IPG strip, were lost from the 2-DE maps. For the other hypothetical proteins, further study is required to understand the lack of their detection by 2-DE. Monitoring of mRNA expression may determine if these proteins are transcribed and processed, and if they could be therefore expected on 2-DE gels. A membrane proteome is the entire complement of membrane proteins present in a cell at a given condition and time. Synthesis of proteins will be induced or repressed in the situation of growing on the artificial culture medium, especially for intracellular bacteria pathogens (Cash, 2006), and therefore, the actual number of proteins, which are the sort of proteins associated with adhesion and invasion observed on a 2-DE gel, is expected to be much lower. For settling the problems of 2-DE in separating membrane proteins, various alternative techniques in gel-based (e.g., blue native-PAGE [BN-PAGE], clear-native-PAGE [CN-PAGE], enzyldimethyl- $n$-hexadecylammonium chloride [BAC], and SDS/SDS [dSDS]-PAGE) and LC-based (free-flow electrophoresis [FFE] and multidimensional protein identification technology [Mud- PIT]) separation platforms have been employed in membrane proteomics.

We established a 2-DE map of the outer membrane subproteome of $B$. henselae using the sodium carbonate extraction method and the lauryl sarcosine extraction method. We identified a total of 10 proteins present in the OM (HbpA, HbpC, HbpD, Pap31, HutA, OMP89, OMP43, Plp, and two novel proteins BH10650 and BH07600) of B. henselae. To complement the inventory of the OMPs, a bioinformatic approach was performed with two programs, immunogenic proteins, adhesion-associated proteins, type I secretion system-associated protein outer membrane efflux protein, type IV secretion system-associated proteins VirB (Schulein et al., 2005), type V secretion system-associated protein autotransporters, type VI secretion-associated protein Pal and hemin-binding surface proteins, thus maximizing the number of protein species in the OM proteome. Although the analysis of detection and identification of membrane proteins remains a difficult task, 2-DE was used to display the soluble and highly abundant OMPs. These findings may help in the further characterization of $B$. henselae OMPs immunogenic candidates. Some of these proteins merit further investigations because of their immunodominant properties, conservation across serotypes, structure and functions, and in vivo expression in hosts.

\section{ACKNOWLEDGMENTS}

The authors gratefully acknowledge Marina Eeremeeva (Viral and Rickettsial Zoonoses Branch, Centers for Disease Control and Prevention, Atlanta, GA, USA) for critical reading the manuscript. Peijing Li, Fanliang Meng and Peng Wang (National Institute for Commu- 
nicable Disease Control and Prevention, Chinese Center for Disease Control and Prevention) are also thanked for supporting techniques. Research supported by grants for major projects of prevention and control technology for major infectious diseases such as AIDS and viral hepatitis (\#2008ZX10004-002) and for the study of surveillance strategies and methods and diagnostic techniques of major vectors and vector-borne disease pathogens (\#2008ZX10004010) from the Ministry of Science and Technology of the People's Republic of China. The authors have declared no conflict of interest.

\section{REFERENCES}

Alsmark CM, Frank AC, Karlberg EO, Legault BA, et al. (2004). The louse-borne human pathogen Bartonella quintana is a genomic derivative of the zoonotic agent Bartonella henselae. Proc. Natl. Acad. Sci. U. S. A. 101: 9716-9721.

Arnold K, Bordoli L, Kopp J and Schwede T (2006). The SWISS-MODEL workspace: a web-based environment for protein structure homology modelling. Bioinformatics 22: 195-201.

Babujee L, Venkatesh B, Yamazaki A and Tsuyumu S (2007). Proteomic analysis of the carbonate insoluble outer membrane fraction of the soft-rot pathogen Dickeya dadantii (syn. Erwinia chrysanthemi) strain 3937. J. Proteome Res. 6: 62-69.

Biswas S, Raoult D and Rolain JM (2008). A bioinformatic approach to understanding antibiotic resistance in intracellular bacteria through whole genome analysis. Int. J. Antimicrob. Agents 32: 207-220.

Boonjakuakul JK, Gerns HL, Chen YT, Hicks LD, et al. (2007). Proteomic and immunoblot analyses of Bartonella quintana total membrane proteins identify antigens recognized by sera from infected patients. Infect. Immun. 75 : 2548-2561.

Burgess AW, Paquet JY, Letesson JJ and Anderson BE (2000). Isolation, sequencing and expression of Bartonella henselae omp43 and predicted membrane topology of the deduced protein. Microb. Pathog. 29: 73-80.

Carroll JA, Coleman SA, Smitherman LS and Minnick MF (2000). Hemin-binding surface protein from Bartonella quintana. Infect. Immun. 68: 6750-6757.

Cash P (2006). Analyzing bacterial pathogenesis at level of proteome. Methods Biochem. Anal. 49: 211-235.

Chenoweth MR, Greene CE, Krause DC and Gherardini FC (2004). Predominant outer membrane antigens of Bartonella henselae. Infect. Immun. 72: 3097-3105.

Dabo SM, Confer AW, Saliki JT and Anderson BE (2006). Binding of Bartonella henselae to extracellular molecules: identification of potential adhesins. Microb. Pathog. 41: 10-20.

Dehio C (2004). Molecular and cellular basis of Bartonella pathogenesis. Annu. Rev. Microbiol. 58: 365-390.

Ebanks RO, Goguen M, McKinnon S, Pinto DM, et al. (2005). Identification of the major outer membrane proteins of Aeromonas salmonicida. Dis. Aquat. Organ. 68: 29-38.

Gasteiger E, Hoogland C, Gattiker A, Duvaud S, et al. (2005). Protein Identification and Analysis Tools on the ExPASy Server. In: The Proteomics Protocols Handbook (Walker JW, ed). Humana Press, Clifton, 571-607.

Geourjon C and Deleage G (1995). SOPMA: significant improvements in protein secondary structure prediction by consensus prediction from multiple alignments. Comput. Appl. Biosci. 11: 681-684.

Hernandez-Mendoza A, Quinto C, Segovia L and Perez-Rueda E (2007). Ligand-binding prediction in the resistancenodulation-cell division (RND) proteins. Comput. Biol. Chem. 31: 115-123.

Higgins MK, Eswaran J, Edwards P, Schertler GF, et al. (2004). Structure of the ligand-blocked periplasmic entrance of the bacterial multidrug efflux protein TolC. J. Mol. Biol. 342: 697-702.

Jungblut PR, Schiele F, Zimny-Arndt U, Ackermann R, et al. (2010). Helicobacter pylori proteomics by 2-DE/MS, 1-DELC/MS and functional data mining. Proteomics 10: 182-193.

Lu Z, Szafron D, Greiner R, Lu P, et al. (2004). Predicting subcellular localization of proteins using machine-learned classifiers. Bioinformatics 20: 547-556.

Maurin M, Gasquet S, Ducco C and Raoult D (1995). MICs of 28 antibiotic compounds for 14 Bartonella (formerly Rochalimaea) isolates. Antimicrob. Agents Chemother. 39: 2387-2391.

Minnick MF, Sappington KN, Smitherman LS, Andersson SG, et al. (2003). Five-member gene family of Bartonella quintana. Infect. Immun. 71: 814-821.

Molloy MP, Herbert BR, Slade MB, Rabilloud T, et al. (2000). Proteomic analysis of the Escherichia coli outer membrane. Eur. J. Biochem. 267: 2871-2881.

Neuhoff V, Stamm R and Eibl H (1985). Clear background and highly sensitive protein staining with Coomassie blue dyes

Genetics and Molecular Research 10 (3): 1789-1818 (2011)

CFUNPEC-RP www.funpecrp.com.br 
in polyacrylamide gels: a systematic analysis. Electrophoresis 6: 427-448.

Ochsner UA, Vasil AI, Johnson Z and Vasil ML (1999). Pseudomonas aeruginosa fur overlaps with a gene encoding a novel outer membrane lipoprotein, OmlA. J. Bacteriol. 181: 1099-1109.

Okusu H, Ma D and Nikaido H (1996). AcrAB efflux pump plays a major role in the antibiotic resistance phenotype of Escherichia coli multiple-antibiotic-resistance (Mar) mutants. J. Bacteriol. 178: 306-308.

Pieper U, Eswar N, Webb BM, Eramian D, et al. (2009). MODBASE, a database of annotated comparative protein structure models and associated resources. Nucleic Acids Res. 37: D347-D354.

Rey S, Acab M, Gardy JL, Laird MR, et al. (2005). PSORTdb: a protein subcellular localization database for bacteria. Nucleic Acids Res. 33: D164-D168.

Rhomberg TA, Karlberg O, Mini T, Zimny-Arndt U, et al. (2004). Proteomic analysis of the sarcosine-insoluble outer membrane fraction of the bacterial pathogen Bartonella henselae. Proteomics 4: 3021-3033.

Riess T, Raddatz G, Linke D, Schafer A, et al. (2007). Analysis of Bartonella adhesin A expression reveals differences between various $B$. henselae strains. Infect. Immun. 75: 35-43.

Schulein R, Guye P, Rhomberg TA, Schmid MC, et al. (2005). A bipartite signal mediates the transfer of type IV secretion substrates of Bartonella henselae into human cells. Proc. Natl. Acad. Sci. U. S. A. 102: 856-861.

Szafron D, Lu P, Greiner R, Wishart DS, et al. (2004). Proteome analyst: custom predictions with explanations in a webbased tool for high-throughput proteome annotations. Nucleic Acids Res. 2: W365-W371.

Tan S, Tan HT and Chung MC (2008). Membrane proteins and membrane proteomics. Proteomics 8: 3924-3932.

Tusnády GE and Simon I (2001). The HMMTOP transmembrane topology prediction server. Bioinformatics 17: 849-850.

Yang S, Clayton SR and Zechiedrich EL (2003). Relative contributions of the AcrAB, MdfA and NorE efflux pumps to quinolone resistance in Escherichia coli. J. Antimicrob. Chemother. 51: 545-556.

Zgurskaya HI and Nikaido H (1999). Bypassing the periplasm: reconstitution of the AcrAB multidrug efflux pump of Escherichia coli. Proc. Natl. Acad. Sci. U. S. A. 96: 7190-7195.

Zimmermann R, Kempf VA, Schiltz E, Oberle K, et al. (2003). Hemin binding, functional expression, and complementation analysis of Pap 31 from Bartonella henselae. J. Bacteriol. 185: 1739-1744.

Zou Q, Yan X, Li B, Zeng X, et al. (2006). Proteome analysis of sorbitol fermentation specific protein in Vibrio cholerae by 2-DE and MS. Proteomics 6: 1848-1855. 


\section{APPENDIX}

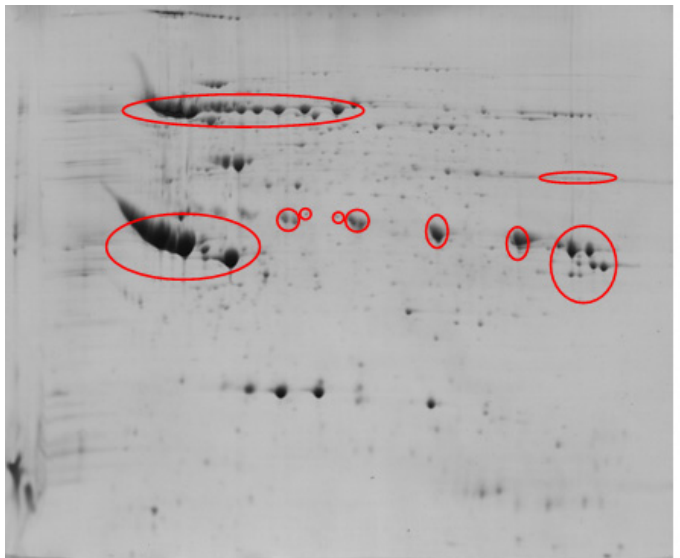

A

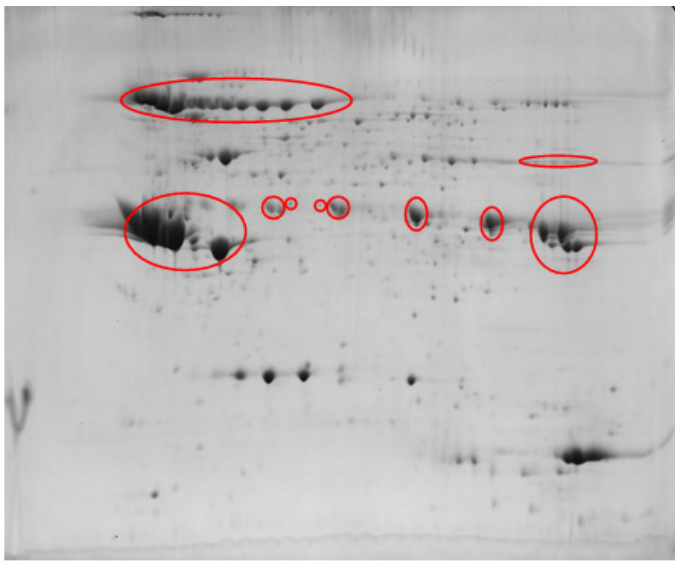

B

Appendix Figure 1. Sarcosine-insoluble Bartonella henselae Houston-1 outer membrane proteins (OMPs) separated by 2-DE, using pH 3-10 IPG and 12.5\% SDS-PAGE. Proteins were stained with Coomassie brilliant blue G-250. A and B were performed under the same conditions. Red circles indicate proteins annotated as OMPs.

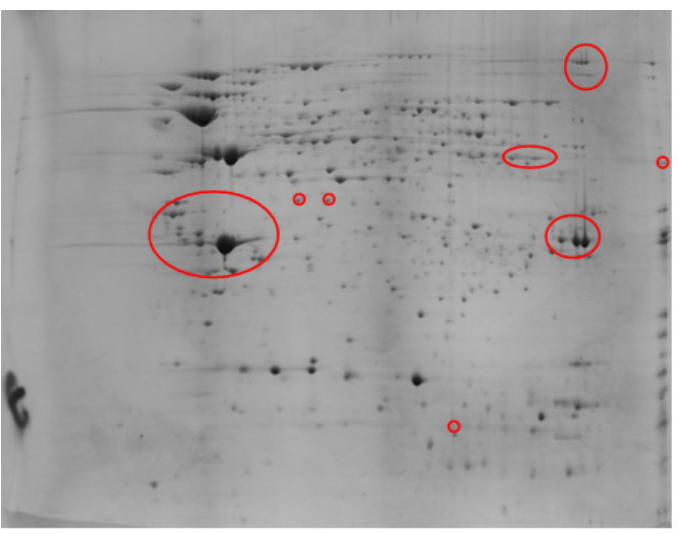

A

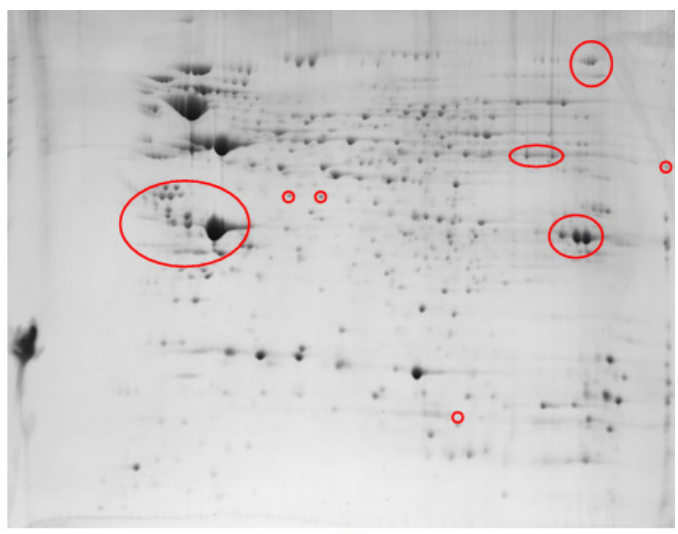

B

Appendix Figure 2. Carbonate-insoluble Bartonella henselae Houston-1 outer membrane proteins (OMPs) separated by 2-DE, using $\mathrm{pH} 3-10$ IPG and $12.5 \%$ SDS-PAGE. Proteins were stained with Coomassie brilliant blue G-250. A and B were performed under the same conditions. Proteins in red circles are annotated as OMPs. 
D.M. Li et al.

1808

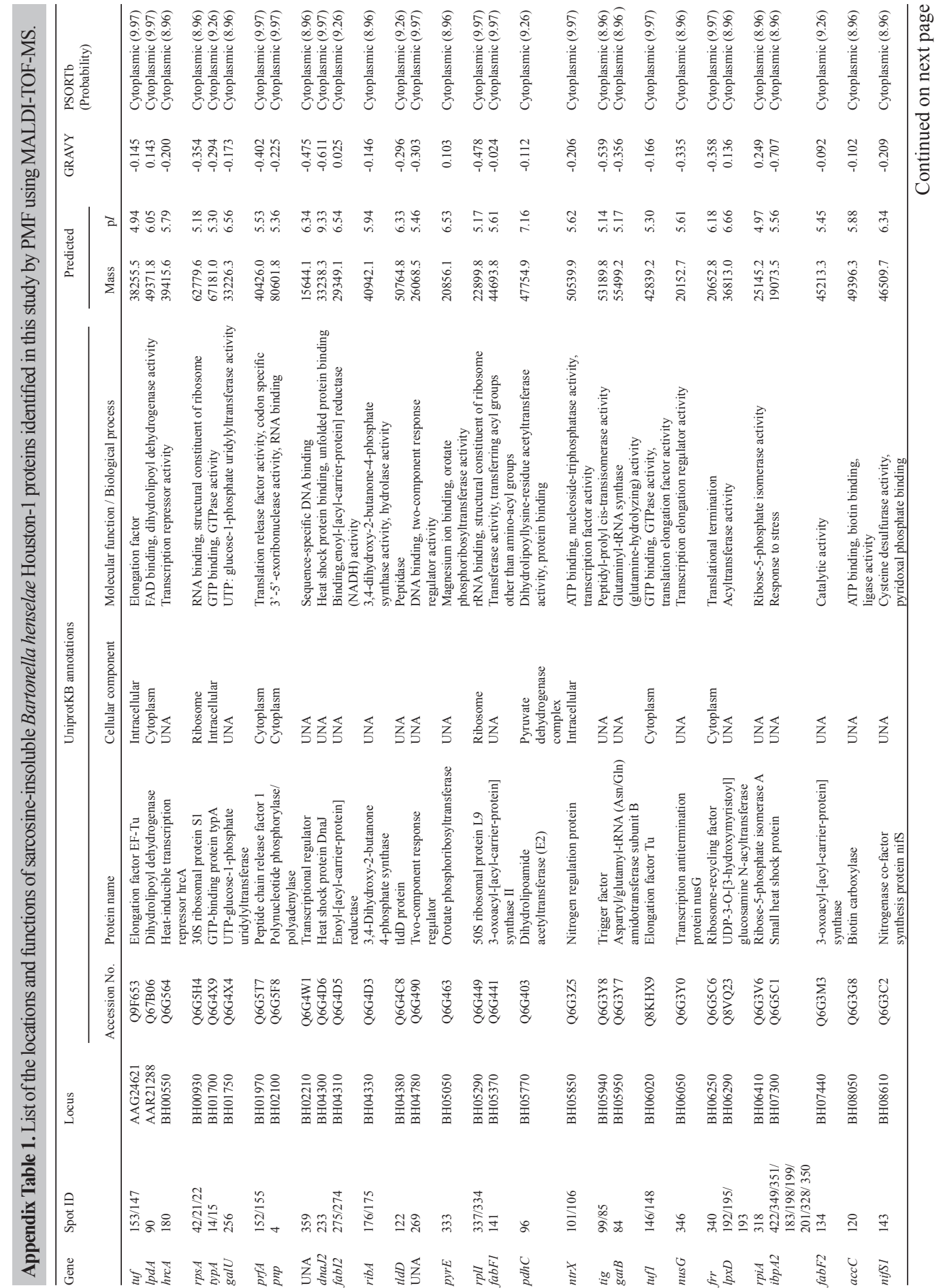


Proteomic and bioinformatic analysis of Bartonella henselae

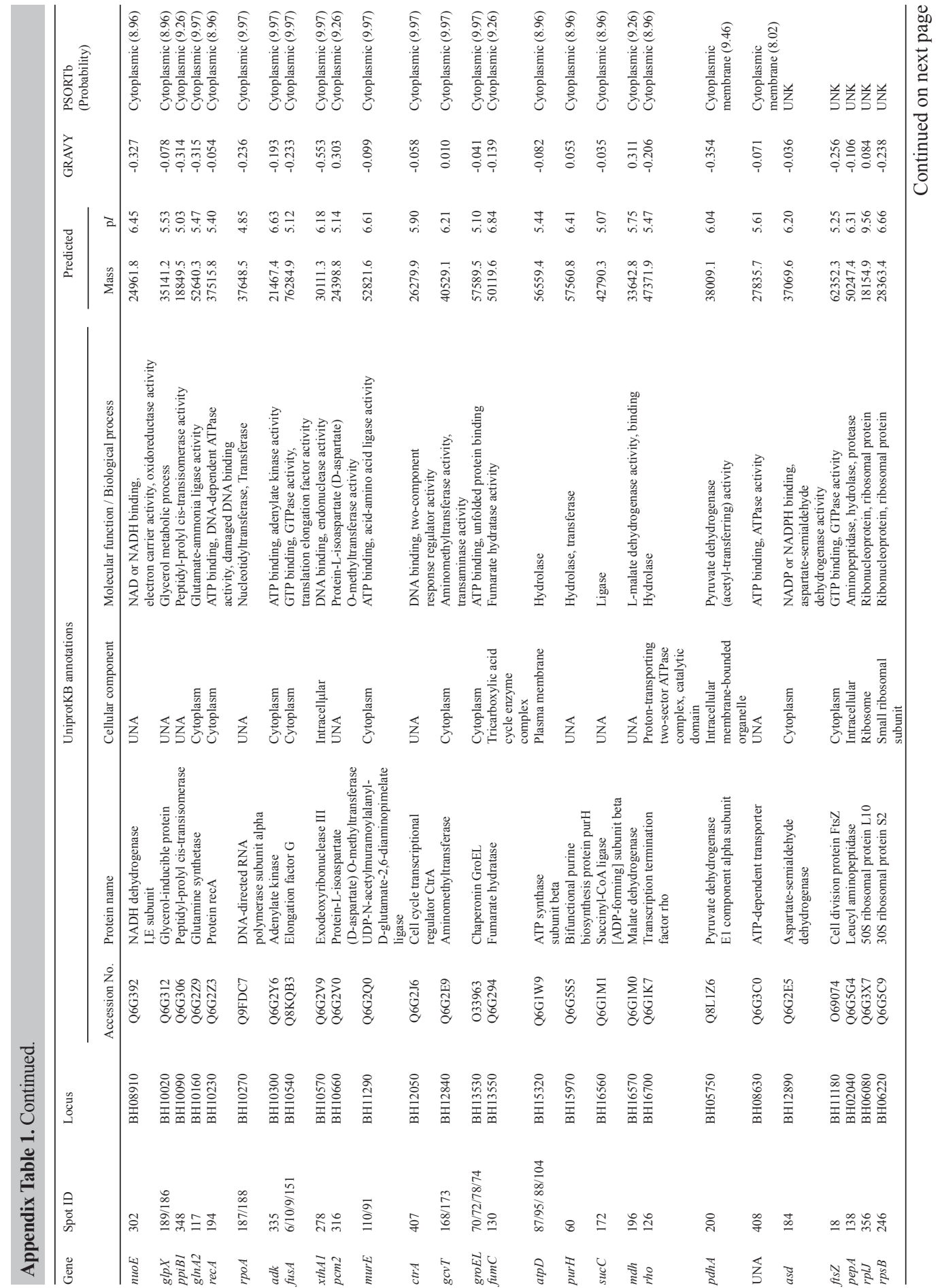


D.M. Li et al.

1810

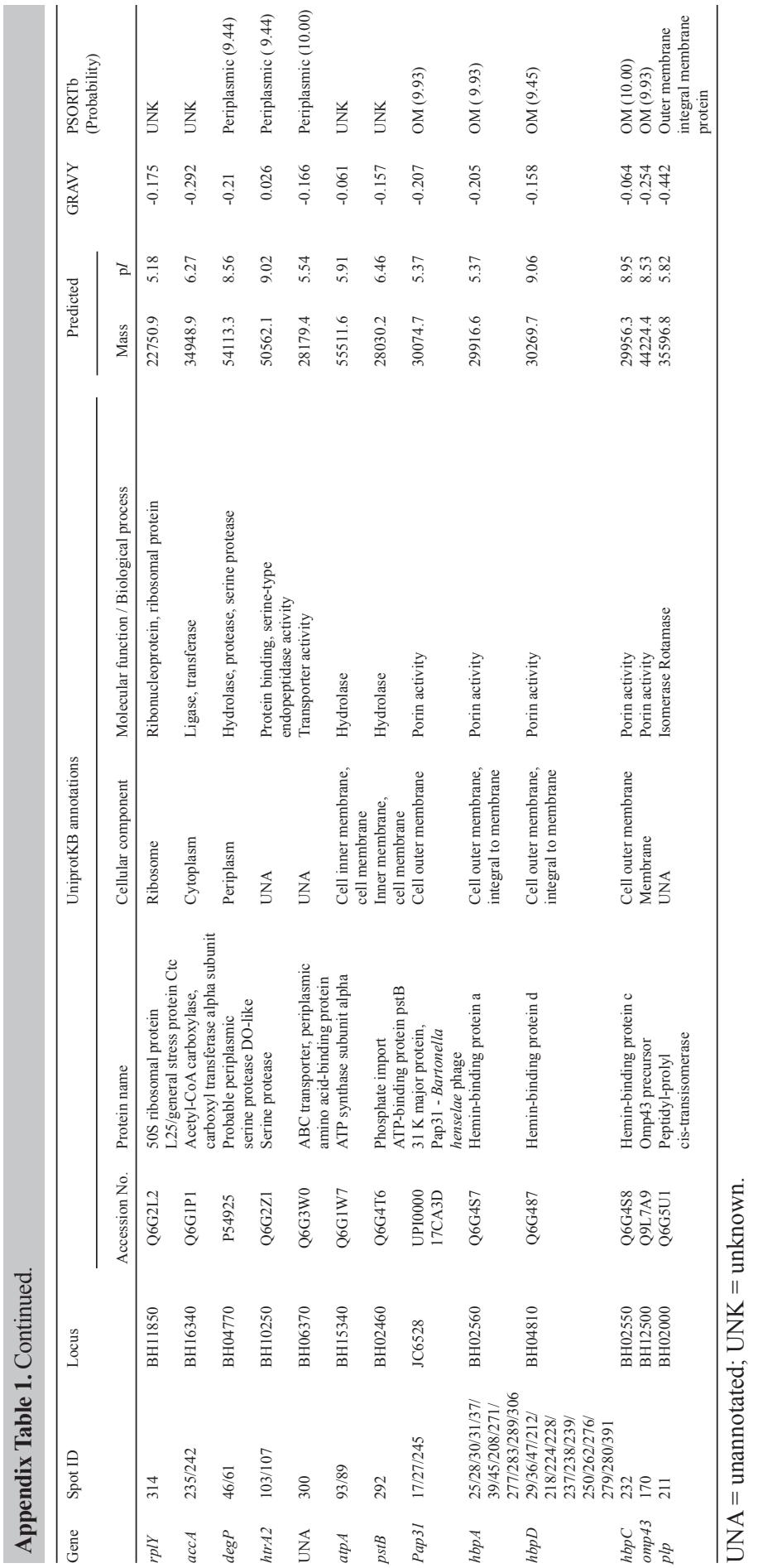




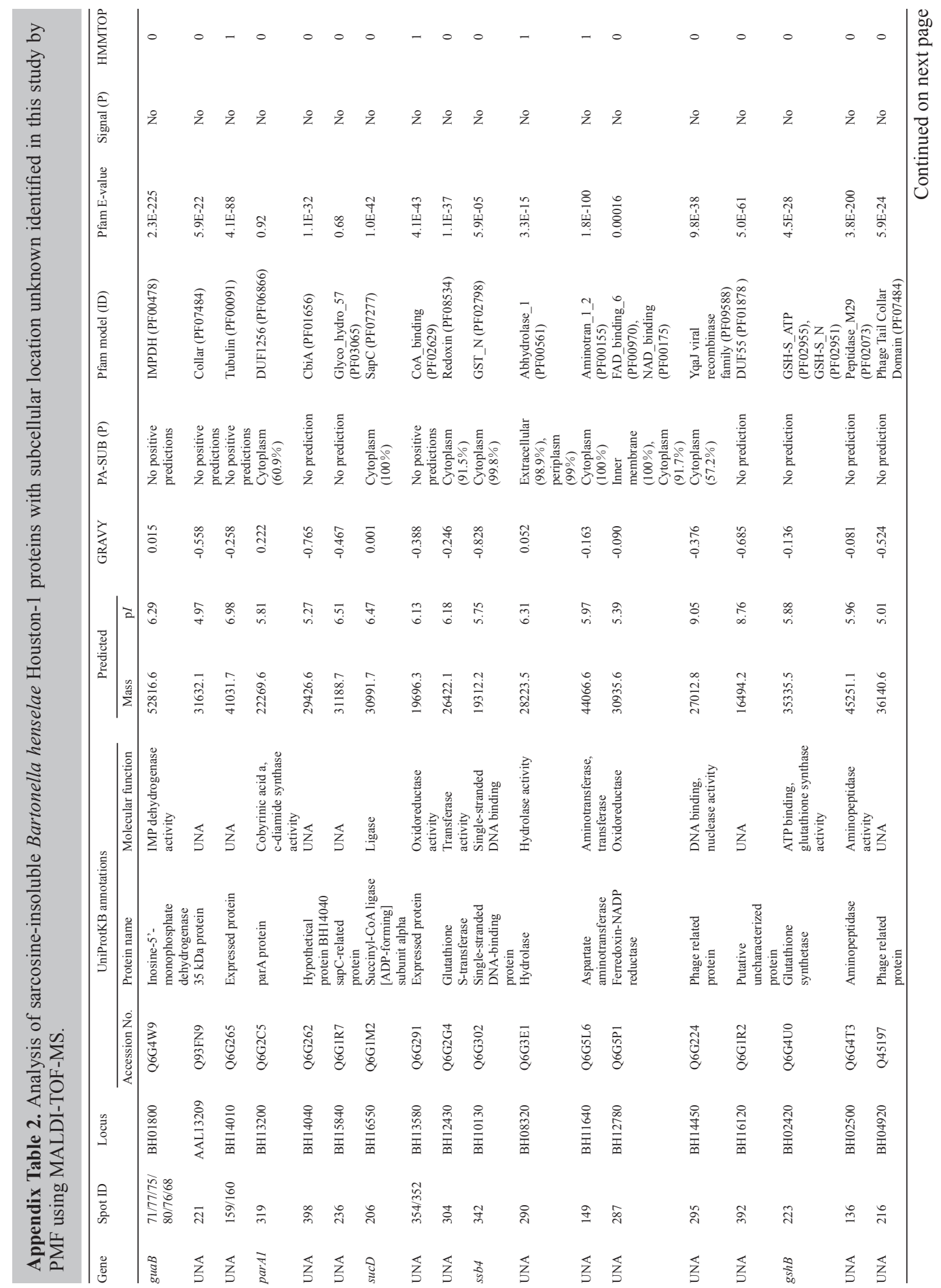


D.M. Li et al.

1812

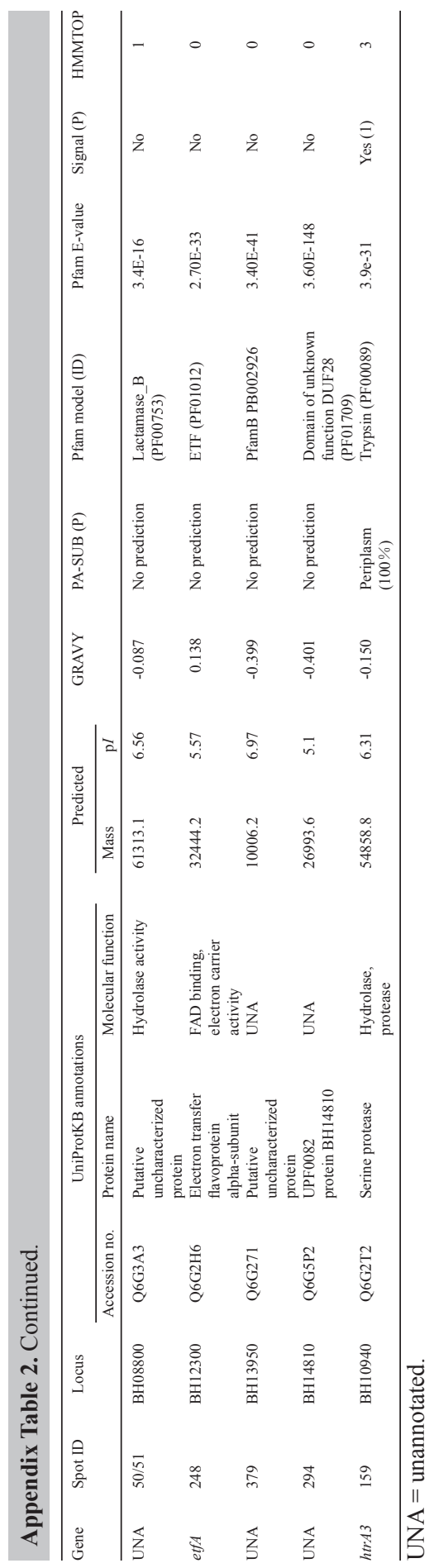

Genetics and Molecular Research 10 (3): 1789-1818 (2011) 
Proteomic and bioinformatic analysis of Bartonella henselae

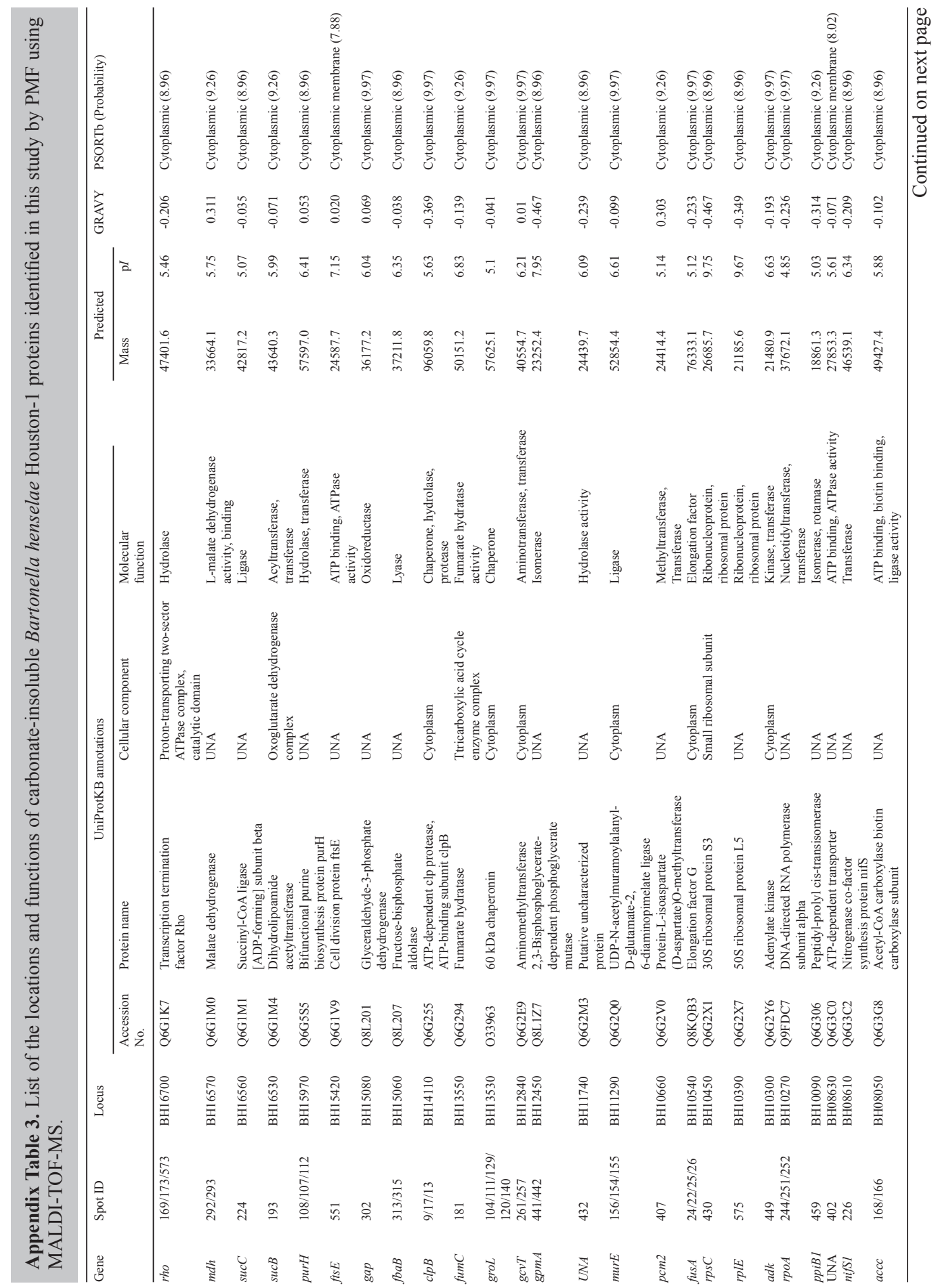


D.M. Li et al.

1814

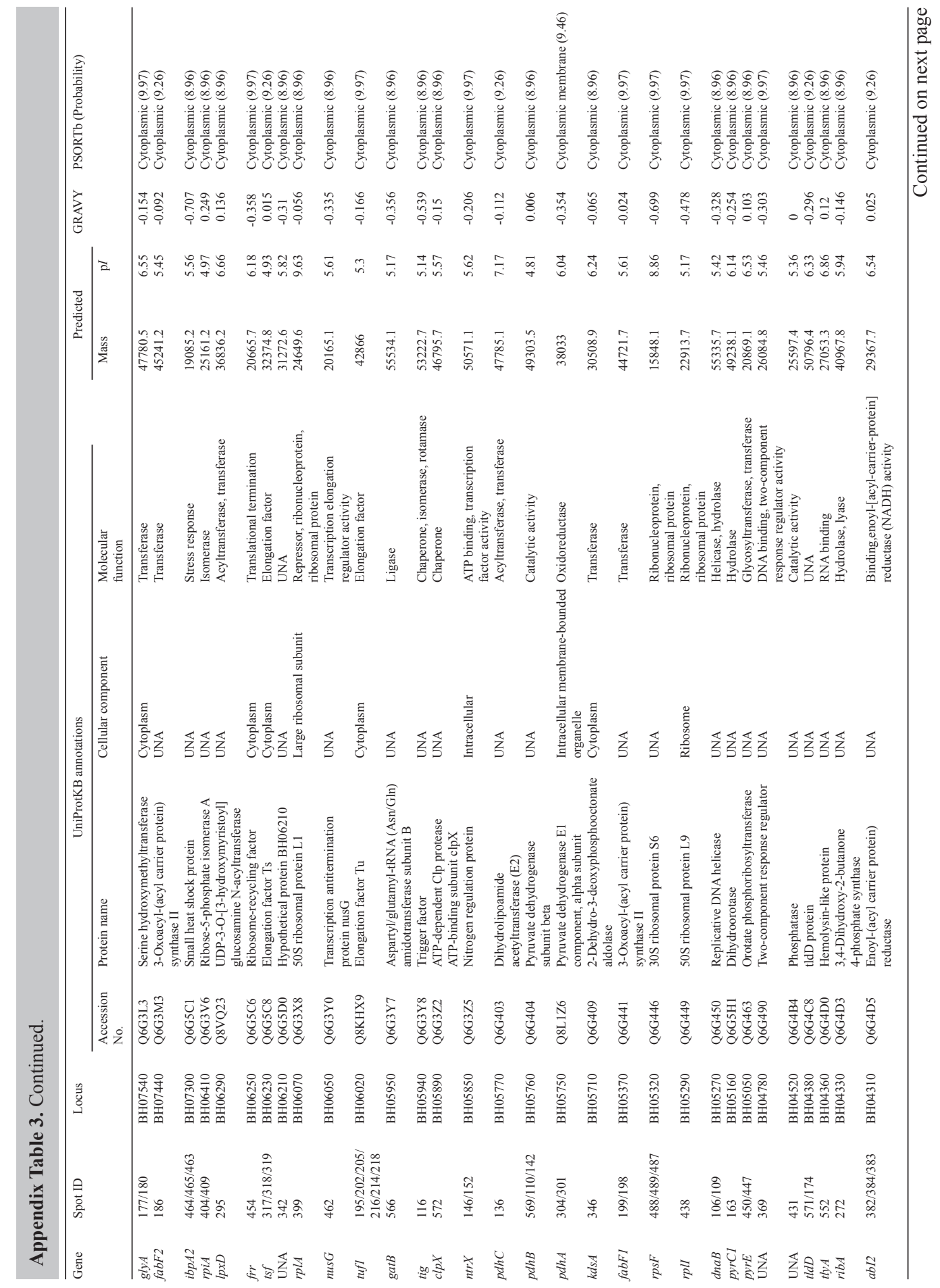


Proteomic and bioinformatic analysis of Bartonella henselae

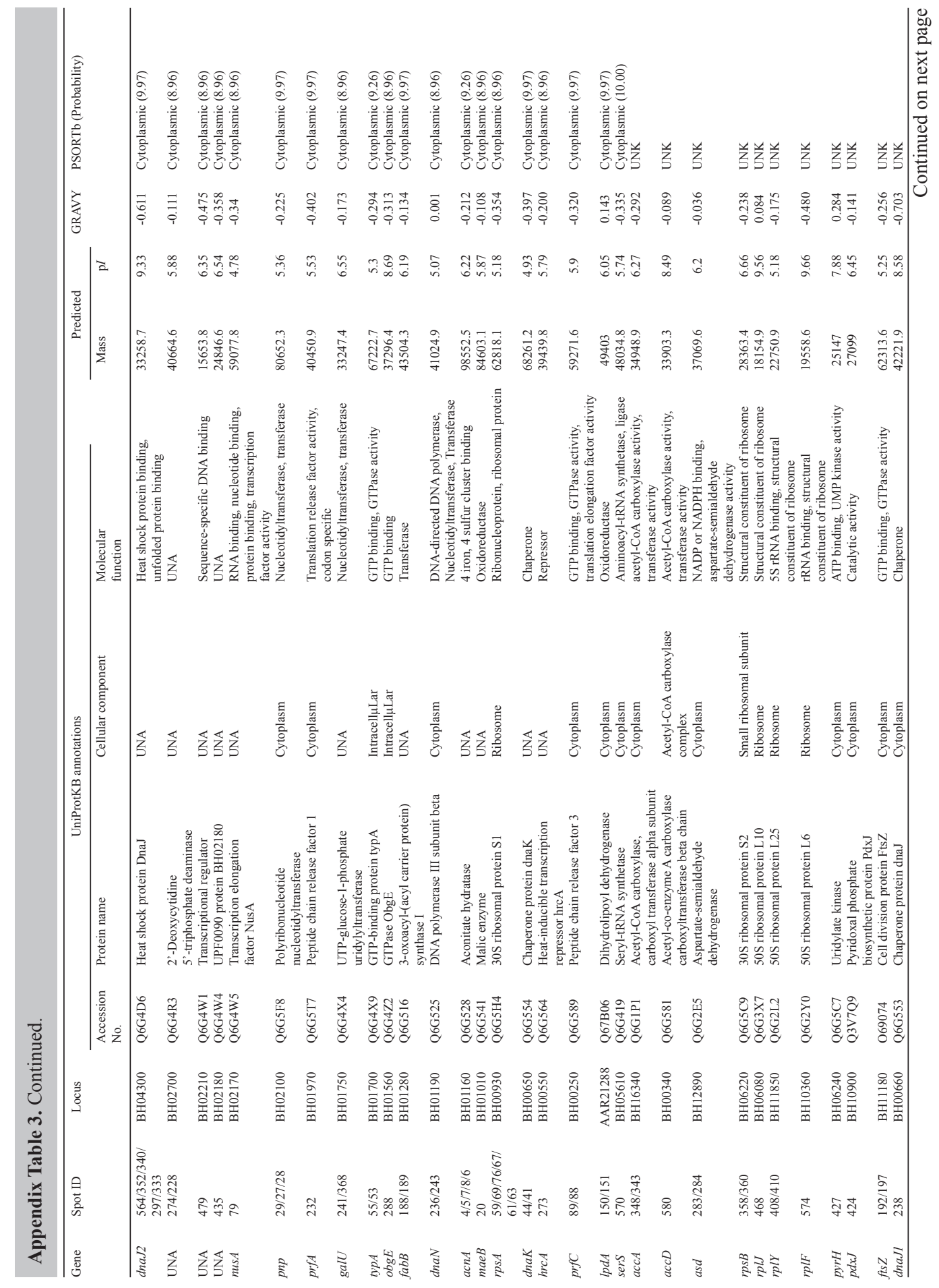


D.M. Li et al.

1816

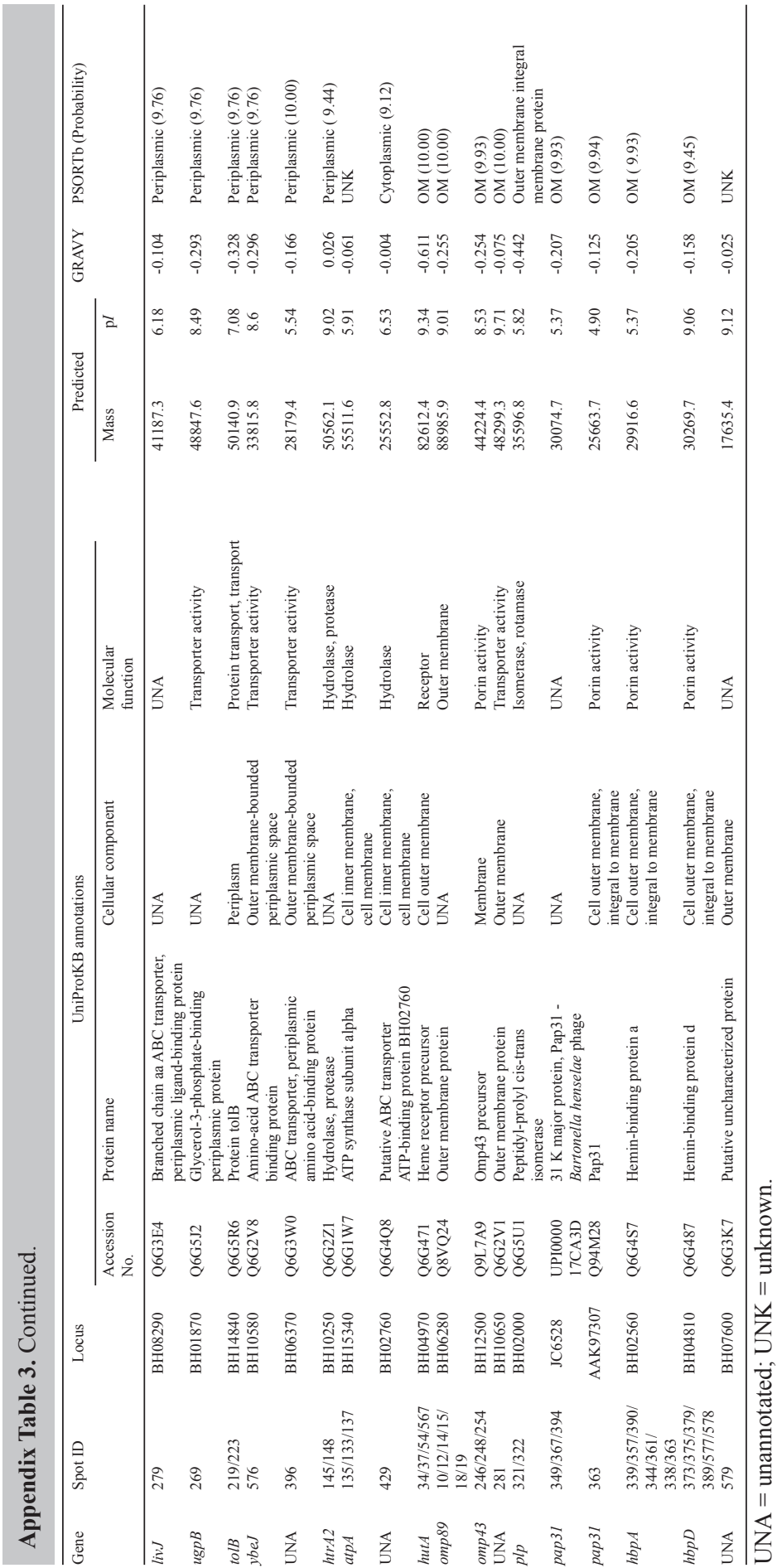


Proteomic and bioinformatic analysis of Bartonella henselae

1817

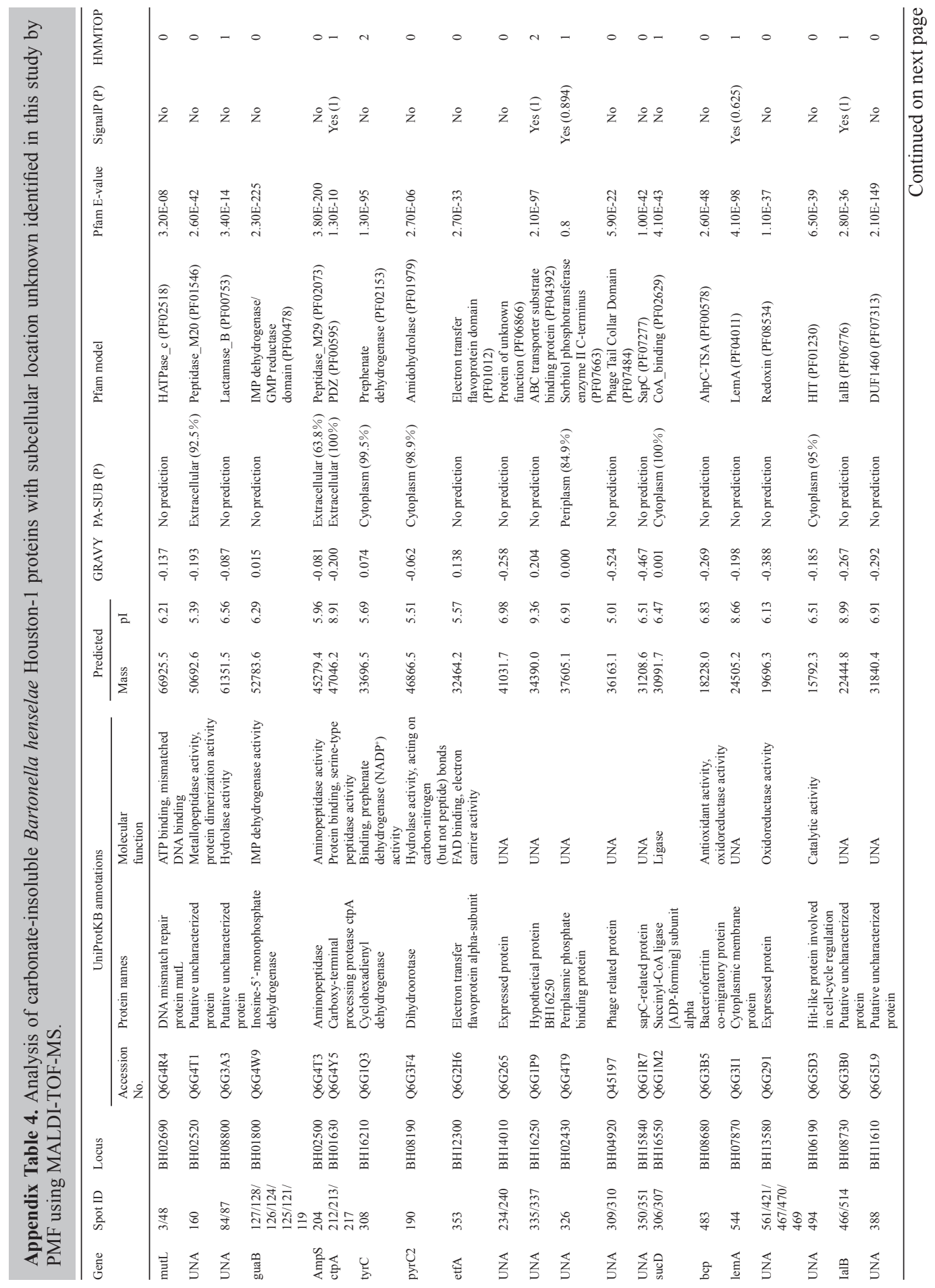

Genetics and Molecular Research 10 (3): 1789-1818 (2011)

CFUNPEC-RP www.funpecrp.com.br 
D.M. Li et al.

1818

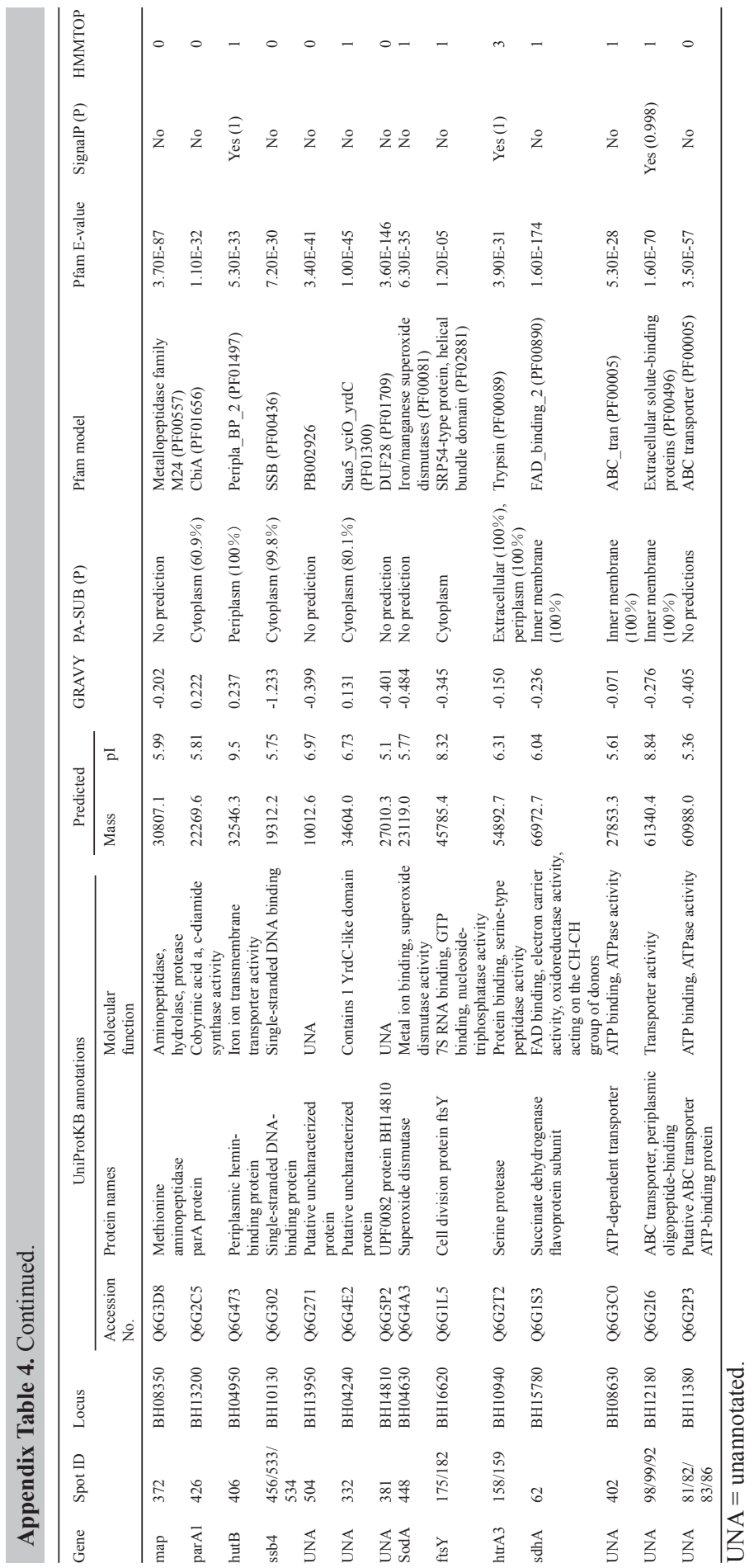

